\title{
Deformation Monitoring and Evaluation of Mountain Slope Stability Combined With Ground-based Radar and Spaceborne InSAR Methods
}

\section{Yanchao Wang (D2319259348@qq.com )}

National Institute of Natural Hazards: Institute of Crustal Dynamics https://orcid.org/0000-0002-61877514

\section{Wenliang Jiang}

National Institute of Natural Hazards: Institute of Crustal Dynamics

Bingquan Li

National Institute of Natural Hazards: Institute of Crustal Dynamics

Yi Luo

National Institute of Natural Hazards: Institute of Crustal Dynamics

\section{Yongsheng Li}

National Institute of Natural Hazards: Institute of Crustal Dynamics

\section{Research Article}

Keywords: ground-based radar, spaceborne InSAR, deformation monitoring, slope stability, time series InSAR

Posted Date: June 1st, 2021

DOl: https://doi.org/10.21203/rs.3.rs-555768/v1

License: @ (i) This work is licensed under a Creative Commons Attribution 4.0 International License. Read Full License 
Deformation monitoring and evaluation of mountain slope stability combined with ground-based radar and spaceborne InSAR methods Author information

Yanchao Wang, Wenliang Jiang, Bingquan Li, Yi Luo, Yongsheng Li

National Institute of Natural Hazards, Ministry of Emergency Management of the People's Republic of China, Beijing, 100085, China

Correspondence: Wenliang Jiang (jiang_wenliang@163.com)

\section{Abstract}

In this paper, ground-based radar and spaceborne Interferometric Synthetic Aperture Radar (InSAR) images were combined to monitor slope stability and analyze the main deformation factors of an ancient landslide on the right bank of the Dajinchuan River in Danba County, Sichuan Province, China. We applied the short baseline set (SBAS) time series strategy with 656 scenes of ground-based radar between September 13-17, 2019, and 62 scenes of Sentinel-1 data from July 2018 to October 2020. Combined with high-resolution satellite images and digital elevation model (DEM) data, we acquired trace and quantitative deformation features and discussed the factors that contributed to slope instability, such as geological structure, topography, external environment and human activities. The largest deformation area detected by ground-based radar is located in the bedrock above the target area with a maximum cumulative deformation of more than $30 \mathrm{~mm}$ during the detection time. The maximum average annual deformation rate detected over the region by spaceborne InSAR is over $40 \mathrm{~mm} / \mathrm{a}$. We analyzed the differences between the ground-based radar and spaceborne InSAR and the reasons for the differences. This study provides references and suggestions for investigating potential landslide risks by combining ground-based radar and spaceborne InSAR technology.

\section{Keywords}

ground-based radar; spaceborne InSAR; deformation monitoring; slope stability; time series InSAR 


\section{Funding}

This work was financially supported by Research Grants from the National Institute of Natural Hazards, MEMC, (grant numbers ZDJ2019-17 and ZDJ2020-04), and the National Natural Science Foundation of China (41772219).

\section{Conflicts of interest/Competing interests}

The authors have no financial or proprietary interests in any material discussed in this article.

\section{Availability of data and material}

The sentinel-1 data and regional geological data can be downloaded from Internet, the ground-based radar cannot be deposited.

\section{Code availability (Not applicable)}

\section{Authors' contributions}

All authors contributed to the study conception and design. Material preparation, data collection and analysis were performed by Yanchao Wang, Wenliang Jiang, Yongsheng Li. The ground-based radar data was collected by Bingquan Li and Yi Luo. The first draft of the manuscript was written by Yanchao Wang and all authors commented on previous versions of the manuscript. All authors read and approved the final manuscript.

\section{Ethics approval}

No conflict of interest exits in the submission of this manuscript, and manuscript is approved by all authors for publication. I would like to declare on behalf of my co-authors that the work described was original research that has not been published previously, and not under consideration for publication elsewhere, in whole or in part. All the authors listed have approved the manuscript that is enclosed.

\section{Consent to participate}

It has been approved by all co-authors.

\section{Consent for publication}

This manuscript's publication has been approved by all co-authors. 


\section{Introduction}

China is among the countries with the most serious geological disasters in the world. Unfortunately, accurately predicting and warning about geological hazards are challenging tasks (Hongqi Chen et al. 2011). At present, more than 300,000 hidden geological hazards have been found in China, but nearly $70 \%$ of the major geological disasters that have occurred in recent years were not found within the scope of these hidden hazards, and a large number of hidden hazards have not been found (Xu 2020). Landslides are one of the most important geological disasters, and they not only threaten human lives but also seriously damage the environment, resources and property. With the sustained and rapid development of the national economy, large-scale projects, such as urbanization, railways and hydropower projects, have been developing in depth. For example, the construction of the Sichuan-Tibet Railway and

71 Therefore, an increasing number of construction projects and engineering projects will be exposed to increased geological hazards, which will increase the disaster risk level.

73 On the other hand, the aggravation of global warming and climate change in recent 74 years has led to an increase in "warming and wetting" of the Tibetan Plateau (Duan et al. 2016), and the influence of major natural disasters and disaster chains will become more significant. In addition, because transformation and destruction of the natural environment caused by human disturbance are better, the balance of the natural environment has changed, and the deterioration of the natural environment will eventually feedback to human society. Therefore, it is of great significance to strengthen the identification and dynamic monitoring of geological hazards to achieve advanced risk perception, early warning and accurate emergency response of geological hazards. Thus, precedures are necessary and important guarantees to reduce the casualties and economic losses caused by geological hazards.

Recently, the rapid development of sky-ground multiplatform measurement technology has provided important technical means for risk assessment, early warning and emergency monitoring of geological hazards. Many scholars have carried out a 
87 large number of studies on the early identification and dynamic monitoring of geological hazards (Casagli et al. 2017; Lu Zhang et al. 2018; Lu et al. 2019). Among these platforms, optical satellites and InSAR satellites are the most widely used at present. However, the role of spaceborne technology is more focused on the early

91 identification of geological hazards. In the field of unmanned aerial vehicles, aerial 92 photogrammetry plays an important role in high-precision geological hazard surveys 93 and emergency observations due to its flexibility and relatively low cost. In addition, 94 ground-based radar technology has also been an important supplement to ground-based observation technology, which can carry out long-distance and high-precision observations of major geological hazards; therefore, it is very important to avoid in situ instrument deployment for monitoring and early warnings of major geological hazards and emergency observations (Luo et al. 2020). At present, the application of ground-based radar observation technology in geological hazard monitoring is still in the experimental and exploration stage.

In this study, the mountain slope stability of an ancient landslide on the right bank of the Dajinchuan River in Danba County, Sichuan Province, China, is monitored by ground-based radar and spaceborne InSAR methods. Combined with high-resolution image and DEM data, we study the trace features and quantitative deformation features of the ancient landslide. The influence of landform, slope direction, geological structure, river erosion, stratum rock group and human activity on the hidden hazards are also analyzed. At the same time, the difference and relationship between the ground-based radar and spaceborne InSAR are analyzed and compared, and the main factors that cause the differences are discussed. This study

111 geological hazards by combining ground-based radar and spaceborne InSAR 112 technology.

\section{2. Study area description}

114 The study area is located in Jiaju village, Danba County, Sichuan Province. Danba 115 County is located from the first to second step of the topographic transition zone in 
116 China, where the terrain is extremely complex and significantly characterized by an 117 alpine canyon landform. The Dadu River cuts across Danba County from north to south 118 (Fig 1), with river channels of 1000 to $3000 \mathrm{~m}$ in depth. In contrast, influenced by the 119 high mountain and canyon topography, Danba County is characterized by the Tibetan 120 Plateau monsoon. Moreover, the area is also characterized by obvious vertical zonality 121 due to topographic factors. With increasing altitude, both the temperature and 122 evaporation decrease gradually; however, the precipitation increases. The precipitation 123 is mainly concentrated between May and September, the rainy season and dry season 124 are obviously different, and the temperature varies greatly from day to night.

125 Danba County is situated in the contact zone of several tectonic blocks, including 126 the Bayankara block and Sichuan-Yunnan rhombic block. Under the action of several 127 phases of mountain building and metamorphism, the geological structures are 128 extremely complicated, with diversified folding structures and interlaced fault 129 structures trending NW. The complex lithologies are mainly metamorphic rocks, and 130 the strata are relatively complete with only a few missing strata (Nie 2018). Geological 131 disasters occur frequently in Danba County and are characterized by sudden occurrence, 132 strong concealment, and significant damage (Minghui Li et al. 2008). With the increase 133 in construction projects, especially the multistage water-power engineering projects in 134 the Dadu River, geological disasters in this region are becoming increasingly serious, 135 and many old landslides have been reactivated.

136 The study area of this paper is located on the right bank of the Dajinchuan River 137 (Fig 2), a tributary of the Dadu River. The study area is also situated at the foot of the 138 right front slope of the old, large Jiaju landslide group, which consists of many 139 secondary landslides that led to multiple bank deformation events along the 140 Dajinchuan River. The observation area of the ground-based radar in this study is the 141 slope bedrock of a secondary ancient landslide. The front edge of the ancient landslide 142 is approximately $1.4 \mathrm{~km}$ in length, and the height difference between the front and back 143 edges of the landslide is more than 700 meters. The general terrain slope exceeds 25 144 degrees according to the DEM data. Two rock fractures extending in the northeast 
145 direction can be clearly interpreted from the Google Earth images in the observation

146 area of the ground-based radar (Fig 2(c)). The upper fracture is approximately $820 \mathrm{~m}$ in

147 length, and the lower fracture is approximately $600 \mathrm{~m}$ in length. To study the

148 deformation feature of this bedrock slope of the ancient landslide, we utilized

149 ground-based radar and the satellite InSAR method. The deformation results measured

150 by the two methods are analyzed, and these results may help to better understand the

151 landslide in similar studies.

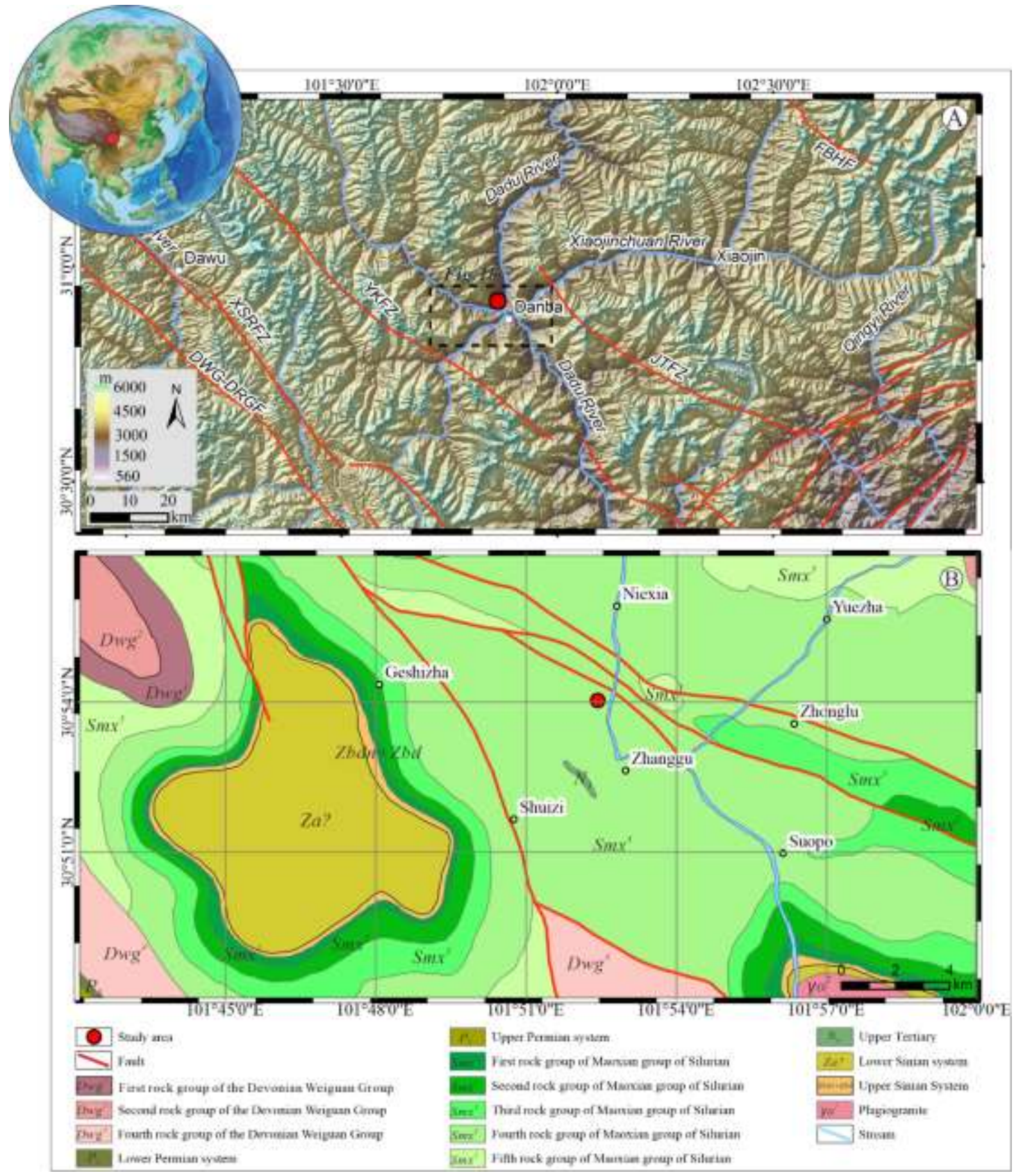

Fig 1(a) Regional hillshade map of the study area. A Shuttle Radar Topography Mission (SRTM)

hillshade map is used as the base map. (b) Regional geological setting surrounding the study area 
156 fault zone; JTFZ: Jintang arc fault; XSHFZ: Xianshui River fault; DWG-GRGF:

157 Dawagou-Dourigou fault; and FBHF: Fubian River fault.
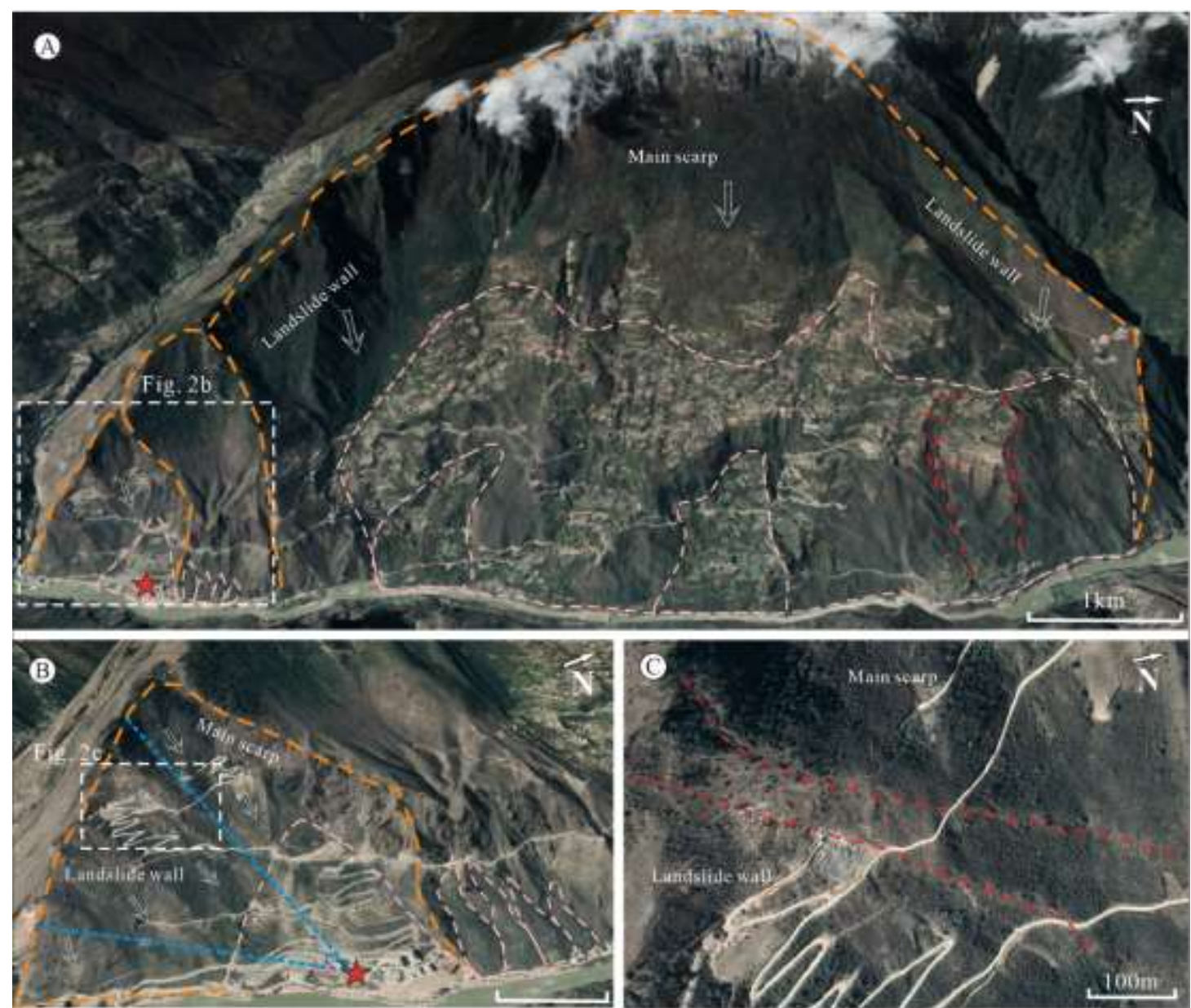

\section{Observation location}

K. - and range of GB-Radar

Slide dircetion of

Debris mass of

ancient landslide

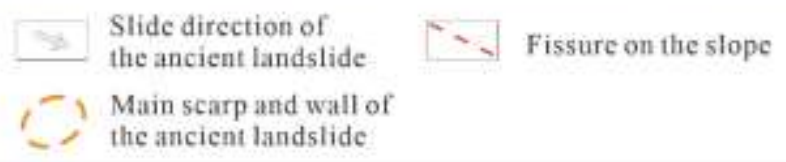

159 Fig 2 Geographic location map. (a) The whole picture of the Jiaju landslide group. (b)The location and range of ground-based radar. (c) The surface fissure on the slope.

\section{3. Data and methods}

\subsection{Measurement principle of ground-based radar}

163 The ground-based radar data used in this study are acquired by the portable radar 164 interferometer GPRI-II (Gamma Portable Radar Interferometer) produced by GAMMA 165 company. This interferometer uses real aperture radar with a radar frequency of 17.2 $166 \mathrm{GHz}$ (Ku band), bandwidth of $200 \mathrm{MHz}$, wavelength of $0.0176 \mathrm{~m}$ and effective 
measurement range from 0.05 to $10 \mathrm{~km}$. The deformation monitoring accuracy can reach the submillimeter level with an azimuth resolution of $6.28 \mathrm{~m}$ (when the distance

169 is $1 \mathrm{~km}$ ) and a range resolution of $0.75 \mathrm{~m}$. The GPRI-II is mounted on a tripod and measured at $360^{\circ}$ by a rotating scanner with three antennas, one transmitting signal and two receiving the echo signal.

GPRI-II uses a frequency-modulated continuous wave (FMCW) to measure the

173 velocity and distance of the target by the frequency differences between the transmitted

174 signal and received signal. This technique is suitable for data acquisition and digital 175 signal processing with low difference frequency signals and simple hardware 176 processing. Compared with SFCW (step frequency continuous wave), GPRI-II can 177 improve the scanning speed and reduce the influence of the atmospheric delay phase on 178 the monitoring precision, reducing the phase distortion caused by system noise in the 179 long-term scanning process. At the same time, GPRI-II can generate a DEM by means 180 of two antennas. The system generally uses the continuous observation mode to 181 continuously observe the target area.

182 The range resolution of GPRI-II is

$$
\Delta d_{s r}=\frac{C}{2 B}
$$

where $\mathrm{C}$ is the speed of light and $\mathrm{B}$ is the bandwidth. As seen from the above equation, the range resolution is independent of the distance between the instrument and the observed target.

The azimuth resolution is the interferometric phase of GPRI-II does not include the terrain phase and the 192 geometric phase component between the two positions; thus, the interferometric phase 193 is

$$
\Delta \varphi=\varphi_{\text {defo }}+\varphi_{\text {atmo }}+\varphi_{\text {noise }}+2 \mathrm{k} \Pi
$$

195 In the formula, $\varphi_{\text {defo }}$ is the deformation phase, $\varphi_{\text {atmo }}$ is the atmospheric delay 
phase, and $\varphi_{\text {noise }}$ is the noise phase.

197 Compared with the spaceborne InSAR system, the ground-based radar system 198 has several unique advantages (Wu et al. 2019; Tiandong Chen 2020). First, the 199 precision of the ground-based radar is higher up to the submillimeter level as its 200 wavelength is shorter. Second, the observation period of ground-based radar is shorter, 201 and the time sampling rate is higher to simplify the phase unwrapping process and 202 achieve rapid real-time monitoring. Third, the ground-based radar system is more 203 portable and flexible because it can be monitored at any time according to the 204 conditions of the disaster, and the observation angle and observation time interval can 205 be adjusted, making it more suitable for slope deformation monitoring. Finally, the 206 ground-based radar installed on the observation station has no influence on the space 207 baseline or orbit error.

\section{$208 \quad 3.2$ Ground-based radar data acquisition}

209 To obtain the echo signal as much as possible and ensure the stability of the 210 platform, the set-up position of GPRI-II should consider the following four conditions 211 (Bingquan Li et al. 2019). The first is good visibility, and the equipment should be set 212 up in a position with high visibility and no obstacles between the equipment and target 213 area. Second, a reasonable observation distance, that is, the appropriate monitoring 214 distance, should be selected according to the actual situation of the site, such as the 215 topography, engineering, hydrology and other conditions. The larger the distance is, the 216 weaker the radar receiving echo signal, and the worse the monitoring effect. The third 217 condition is that the equipment should be placed on a stable observation platform to 218 reduce the influence of any small equipment movement on the observation accuracy. 219 The last condition is a suitable viewing angle. The smaller the angle is, the more sensitive the radar is to the intensity of the deformation signal, but it is disadvantageous

221 to receive the echo signal. In ground-based radar deformation monitoring, the observation parameters should be adjusted at the beginning according to the environmental factors and the quality of the observation data because the subsequent data processing accuracy has a great impact. 
In this study, the instrument was set up in the Jiajuzangzhai tourist center in a continuous observation mode. The monitoring time was from 8:27 to 21:37 on 227 September 13, 2019, and from 16:46 on September 15 to 13:26 on September 17, 2019. 228 The time interval between the two receiving antennas was approximately 10 minutes 229 and one scene, and the total number of images was 656 scenes. The observed parameters are shown in Table 1.

Table 1 Measured parameters of the ground-based radar

\begin{tabular}{lc}
\hline Index & Parameter \\
\hline Platform location & $101.878^{\circ} \mathrm{E}$, \\
& $30.905^{\circ} \mathrm{N}$ \\
Platform elevation & $1927.3 \mathrm{~m}$ \\
Measurement range & $0.45-1.3 \mathrm{~km}$ \\
Coherence & 0.35 \\
threshold & \\
Antenna-pitch & $20^{\circ}$ \\
Azimuth & $229.3^{\circ}$
\end{tabular}

GPRI-II ground-based radar and spaceborne InSAR have basically the same time series analysis process; the largest difference is that the ground-based radar spatial baseline is 0 , without image registration and terrain phase compensation. The processing flow of ground-based radar data mainly includes data preprocessing, interference processing, coherent point extraction, phase filtering, phase unwrapping, atmospheric correction, time series analysis and geocoding (Wang et al. 2019a; Wang et al. 2019b).

241 During the process of coherent point extraction, an adequate number of high 242 quality coherent points are very important to the precision of deformation monitoring 243 results. The methods of coherence point extraction mainly include the amplitude 244 departure threshold method, local coherence method (coherence coefficient threshold 
method) and nonlocal method. In this paper, a nonlocal method is used to extract

coherent points by selecting homogeneous or similar pixel estimates from the 247 surroundings of each resolution unit.

248 In the process of phase unwrapping, there is a $2 \mathrm{k} \pi$ relation between the initial 249 phase and the true phase in the interferogram. The initial phase is the winding phase 250 between $-\pi$ and $\pi$, which is the main value of the true phase. The interference phase 251 needs to be decoded to obtain the true phase. Considering the stability and time effect 252 of phase unwrapping, the three-dimensional phase unwrapping method is adopted in 253 this paper.

254 Atmospheric correction is also necessary for ground-based radar data (Xining Zhang et al. 2017). Ground-based radar relies on the phase information of radar signals

256 for ranging, but the accuracy of ranging is affected by the changes in the refractive 257 index of the radar signals because of the atmosphere. Even for short-term monitoring, 258 shortwave band ground-based radar is also very sensitive to weather changes, so 259 improving the measurement error caused by atmospheric phases has become the key technology to improve the observation accuracy of ground-based radar. In this paper, an

261 iterative decomposition model is used to correct the effect of atmospheric variations on the deformation results.

263 We use the singular value decomposition method ( $\mathrm{Li}$ et al. 2013) to generate the 264 deformation time series diagram. The deformation characteristics, including the spatial 265 distribution, deformation intensity and future development trend, can be estimated by 266 the time series map of deformation, which provides a basis for emergency response.

\subsection{Other auxiliary data}

To investigate the features of the slope, as well as for comparison with the deformation results obtained by ground-based radar GPRI-II, remote sensing data from

270 different platforms were also employed, including spaceborne InSAR and 271 high-resolution Google Earth images. A total of 62 scenes of Sentinel-1 data from July 2722018 to October 2020 were selected for deformation analysis.

273 Other auxiliary data, including geological maps and meteorological and 
274 hydrological data, were also employed in the study.

\section{4. Results and analyses}

\section{$276 \quad 4.1 \quad$ Deformation results of ground-based radar}

The effective monitoring time of ground-based radar is from 8:27 on 13 278 September to 21:37 on 13 September and from 16:46 on 15 September to 13:26 on 17 279 September. The maximum monitoring distance is approximately $1300 \mathrm{~m}$, and the 280 minimum monitoring distance is approximately $450 \mathrm{~m}$. According to the processing 281 flow in section 3.3, we set the parameters, which include the unit window size and time 282 baseline. Since the data format of the data acquisition system synchronized to the 283 ground-based radar data processing system is binary, it needs to be converted to MAT 284 format. The average coherence criterion is used to extract the coherent points, and the 285 nonlocal coherence algorithm is used to set the coherence threshold value to 0.35 , the nonlocal window to 15 , the similarity threshold value to 0.9 , the minimum similarity 287 point to 10 , and the maximum similarity point to 45 . Some of the differential 288 interferograms produced during ground-based radar data processing are shown in Fig 3. 289 The numbers at the top of each figure represent the observation dates of the two data 290 points used to generate the differential interferograms. As shown in Fig 4, there is 291 obvious deformation in the monitoring area. The main deformation area is above the 292 continuous curve. The maximum cumulative deformation is more than $30 \mathrm{~mm}$. 

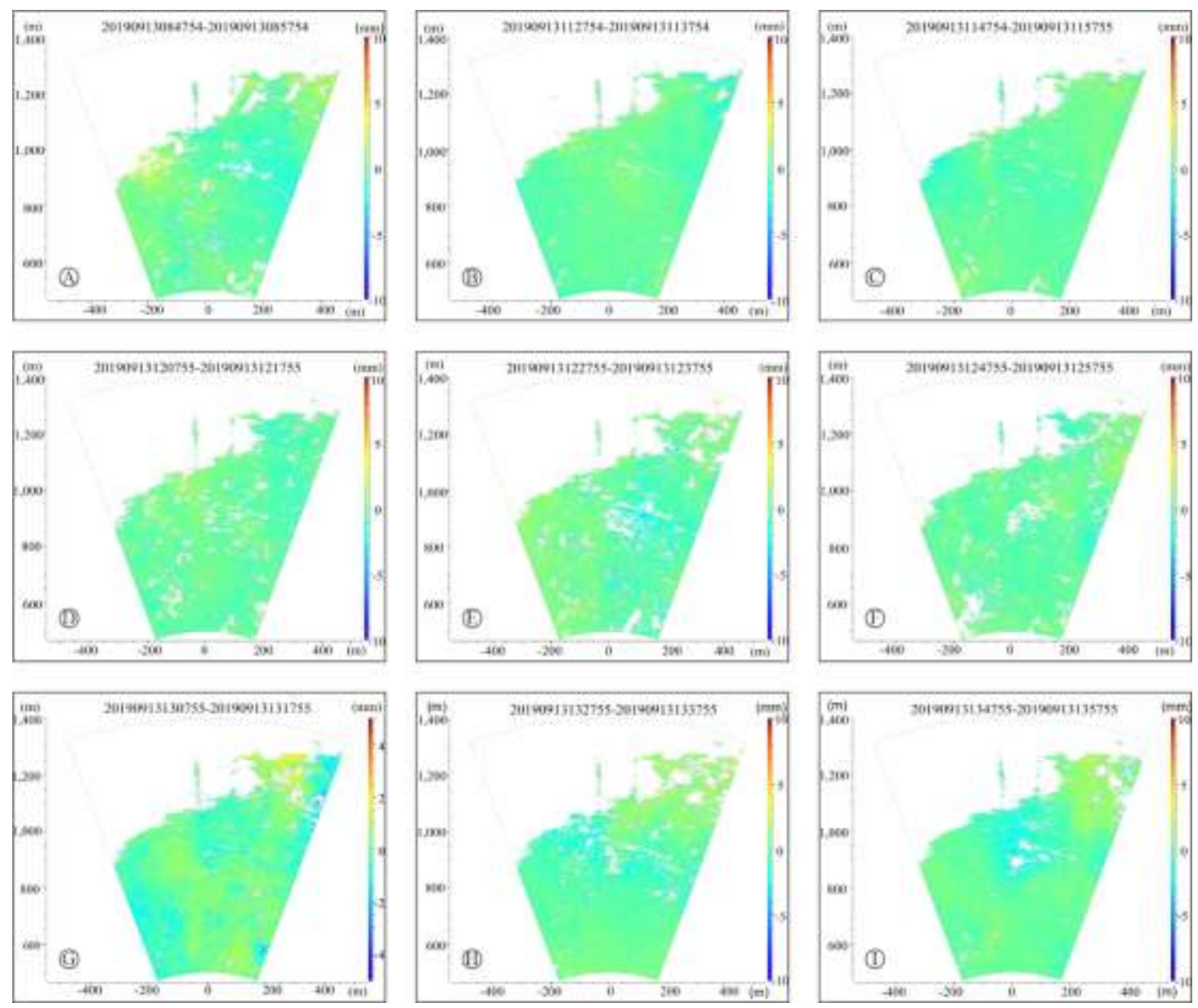

Fig 2 Examples of differential interferograms generated during the processing of ground-based radar data. The two numbers in the upper part of each figure denote the observation dates of two data points used to generate the differential interferogram. $20190913084754-20190913085754$ denotes the differential interferogram generated between two data points observed at $8 \mathrm{~h} 47 \mathrm{~m} 54 \mathrm{~s}$ on September 13, 2019, and at 8 h $57 \mathrm{~m} 54 \mathrm{~s}$ on September 13, 2019. The origin point of the coordinate system is the position of the ground-based radar. 


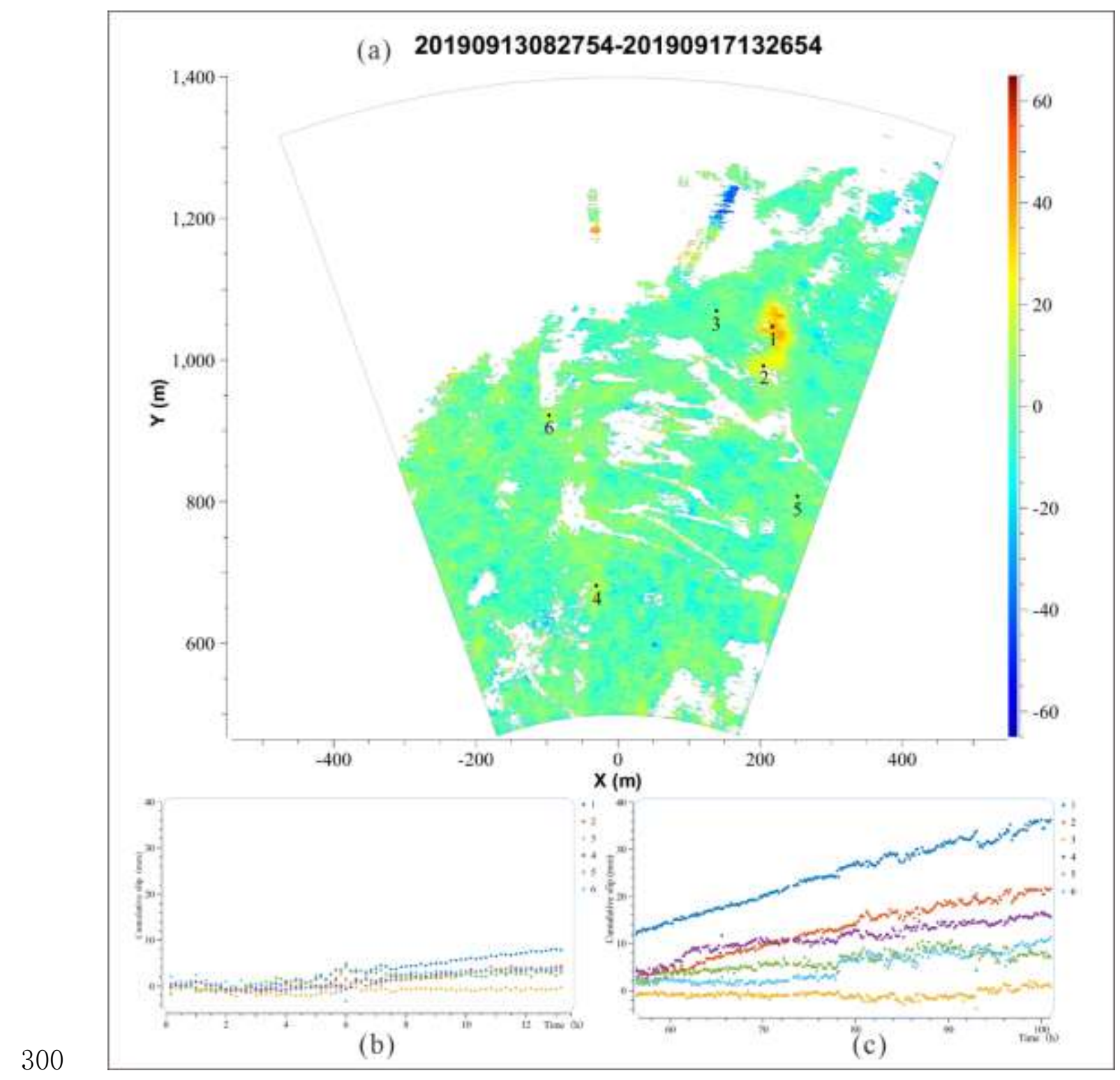

301 Fig 4 (a) Cumulative slips of the slope deformation along the LOS direction measured by the

302 ground-based radar device. The number at the top of the figure represents the time when

303 ground-based radar began and ended observations, that is, the observation time range of the

304 cumulative deformation map generated; and $20190913082754-20190917132654$ represents

305 ground-based radar observation time from 8:27:54 on September 13, 2019 to 13:26:54 on

306 September 17, 2019. The origin of the coordinates represents the position of the ground-based

307 radar. (b) and (c) are the results of the accumulated deformation of the selected points in the time series

308 of $0 \sim 13.5 \mathrm{~h}$ and $56 \sim 101 \mathrm{~h}$, respectively.

$309 \quad 4.2$ Deformation results from spaceborne InSAR

310 Sixty-two scenes of Sentinel-I downorbiting data covering the study area from 
311 July 2018 to October 2020 were processed using GAMMA software, and the average

312 annual deformation rate of the study area over this period was obtained using the short

313 baseline set (SBAS) processing method (Fig 5(a))(Yongsheng Li et al. 2013). The

314 maximum average annual deformation rate in the region is over $40 \mathrm{~mm} / \mathrm{a}$. The main

315 deformation areas monitored are located along the banks of the Dadu River and its

316 tributary, the Dajinchuan River. These deformation areas all have different degrees of

317 human activities, such as road construction.

318 In the observation area of ground-based radar, the gray line in Fig 5(a), three 319 points are selected for time series analysis. The result of the line-of-sight cumulative 320 deformation is shown in Fig 5(b). The maximum cumulative deformation is 321 approximately $80 \mathrm{~mm}$, which is located in the lower part of the continuous bedrock 322 curve of the landslide's back wall. 


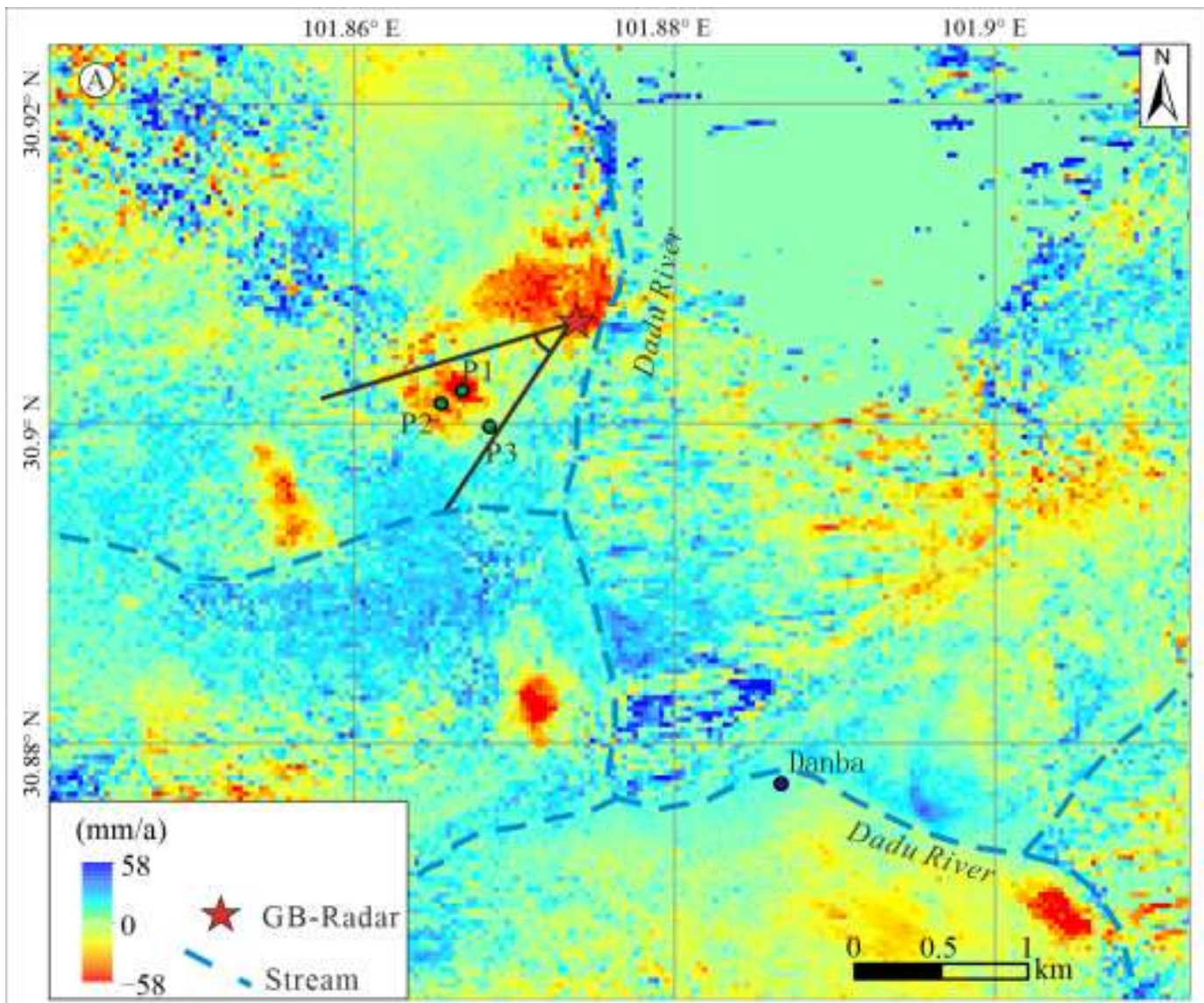

(B)

Time series analysis

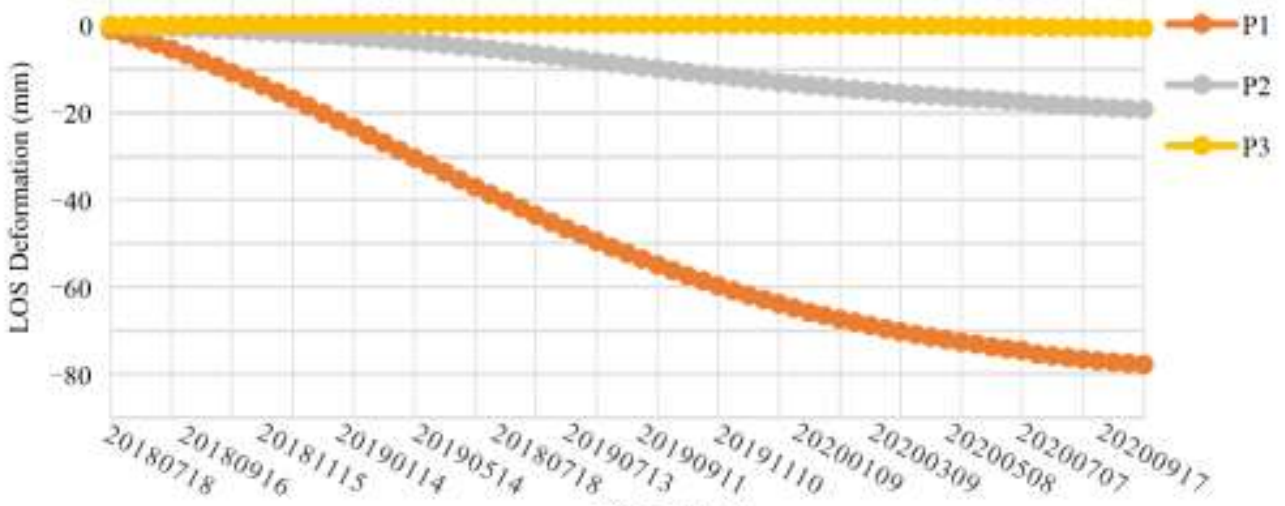

Time (day)

324 Fig 5(a) Regional annual deformation rate map measured by Sentinel-1 data, and P1, P2 and P3 are the three points selected in the observation area of ground-based radar. The gray line is the scanning angular scope of ground-based radar. (b) The line-of-sight cumulative deformation map of three selected points P1, P2 and P3 in the study area.

\section{Discussion}


We match the ground-based radar and spaceborne InSAR data accurately and

331 superpose to the Google Earth 3D image (Fig 6) to compare the image features of 332 different deformation regions. According to the interpretation of satellite remote 333 sensing images, the main target area of this observation is located on the right wall of a 334 pre-existing ancient landslide. The accumulation body of the early ancient landslide is 335 mainly located at the left foot of the ancient landslide, which is the upper part of the 336 scenic area. Some accumulation bodies remain on the right side of the ancient landslide. 337 The target area observed by ground-based radar is mainly on the right side of the ancient landslide, and the back wall is the blind area, which is not effectively covered.

By monitoring the right wall of the ancient landslide with ground-based radar, some deformation is observed in the area. The largest deformation area detected by ground-based radar is located in the bedrock above the target area. The maximum deformation area is approximately $150 \mathrm{~m}$ across the slope and $300 \mathrm{~m}$ up and down the slope. This deformation belongs to the back wall bedrock zone of the pre-existing ancient landslide body and is a push-type landslide.

At the same time, in the deformation map obtained by spaceborne InSAR 347 bottom and upper parts. The bottom deformation region is the left front accumulation of 348 the pre-existing landslide body, which is the area of continuous curving road in the 349 upper part of the scenic spot. The upper deformation region is located in the lower part 350 of the maximum deformation region observed by ground-based radar and corresponds 351 to the continuous curve region on the right wall of the landslide. The deformation of 352 two continuous curved road areas is the result of road construction and can be found in 353 the InSAR long time series result. In contrast, the maximum deformation region 354 observed by ground-based radar reflects the effect of rainfall on slope stability due to 355 the September flood season. The deformation in this area is at a large scale, and local 356 periodic deformation occurs in relation to the flood season. 


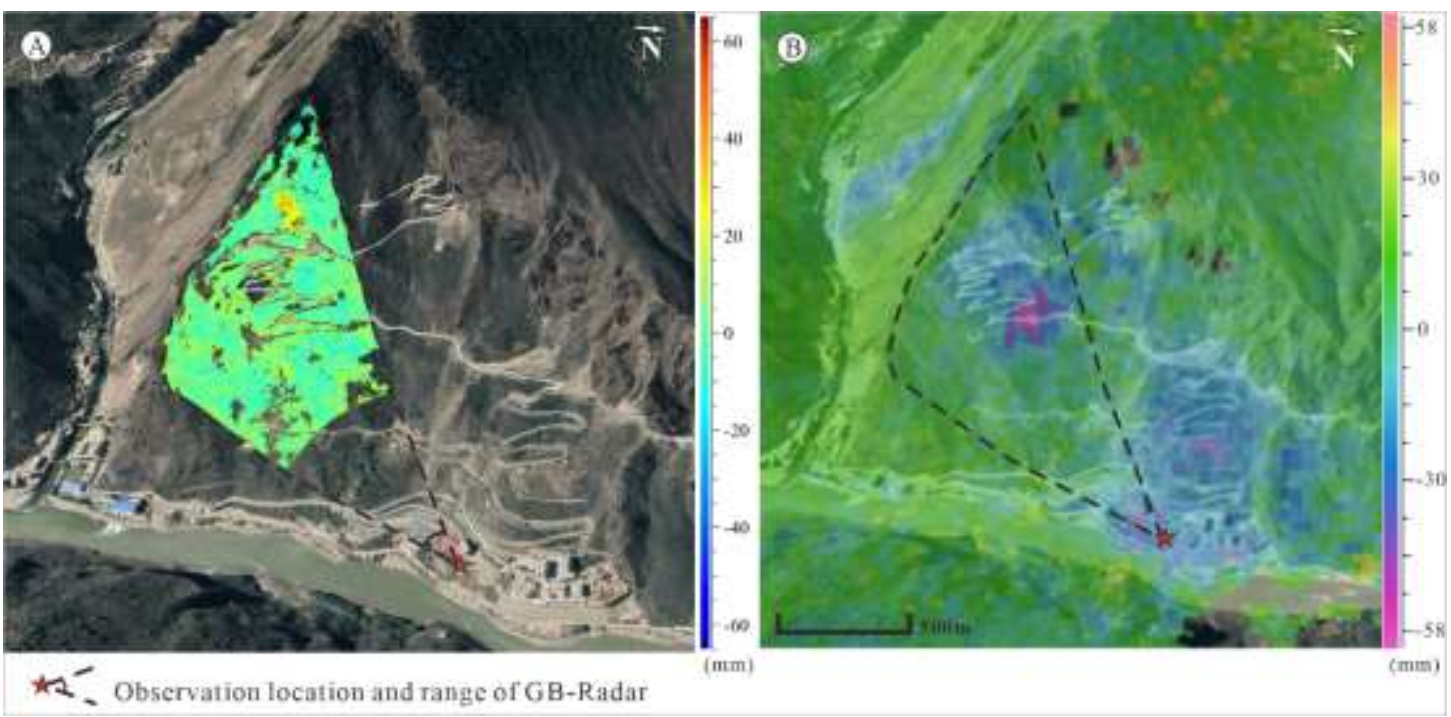

Fig 6(a) Map of ground-based radar monitoring results superimposed on Google Earth;

(b) Map of Sentinel 1 monitoring results superimposed on Google Earth.

\subsection{Main factors influencing slope deformation}

In general, the factors that affect the stability and deformation of geological slopes include geological structure, topography, external environment and human activities.

363 Based on the observational results analysis, deformation is the result of these 364 abovementioned factors.

365 In terms of geological structure, Danba County lies at the intersection of three 366 important active tectonic belts, namely, the northwest Xianshui River Fault Zone, the 367 northeast Longmen Mountain thrust zone and the nearly south-north Anninghe Fault 368 Zone. These three fault zones are all active Holocene fault zones with important 369 seismogenic tectonic settings. Geological hazards in this area are prone to occur 370 because of strong tectonic activity and broken internal blocks under the influence of 371 three active tectonic belts. In addition, the block is located at the front of the Bayankara 372 Block and is in a strong uplift region along the Longmen Mountains tectonic belt. 373 Therefore, this region is characterized by high mountains and deep valleys, and rapid 374 and serious valley undercutting is taking place. The slope angle on the left bank of the 375 river is $36^{\circ}$, and the slope gradient on the right bank is more than $30^{\circ}$. Under the 376 influence of both the uplift of the mountain body and the deep cut of the valley, the 377 increase in the effective open plane formed at the front of the deformation body 378 increases the gravitational potential energy of the slope, leading to the decrease in the 
stability of the slope, and creep deformation of the slope easily occurs under the action of gravity. There are cracks in the broken rock of the bedrock slopes, and rainfall can easily permeate the bedrock, which promotes slope sliding along the bedding surface and affects the stability of slopes. Therefore, strong tectonic activity is the most important factor for the development of geological hazards in Danba County.

In terms of topography and geomorphology, the slope angle of a geological body is an important factor that affects its stability. Generally, geological bodies with slope angles greater than 10 are subject to unstable deformation under the action of gravity (Donnarumma et al. 2013; Luo et al. 2020). According to the regional DEM, the slope angle of the whole terrain is more than $30^{\circ}$ and the gradient is more than 0.58 , while the slope angle of the local slope of ground-based radar is more than $20^{\circ}$ and the gradient is more than 0.41 (Fig 7). Whether considering the whole terrain or the local terrain, the slope of the terrain is very large, and it easily loses stability and deforms under disturbances by internal structural factors and external artificial factors.

In addition, there is a gentle platform in the upper part of the observation slope, which presents as a low-slope above and steep characteristics below over the whole terrain. This topographic feature is not conducive to rapid drainage of heavy rainfall during the flood season (Luo et al. 2020). Under the condition of poor drainage at the top, the accumulated water will gradually permeate into the interior of the formation, thus acting as a lubricant in the interior of the rock formation, causing the slope to be more prone to instability and deformation under the action of gravity. This finding also shows that the deformation observed by ground-based radar in this study is mainly concentrated in the flat-top area of the platform. 


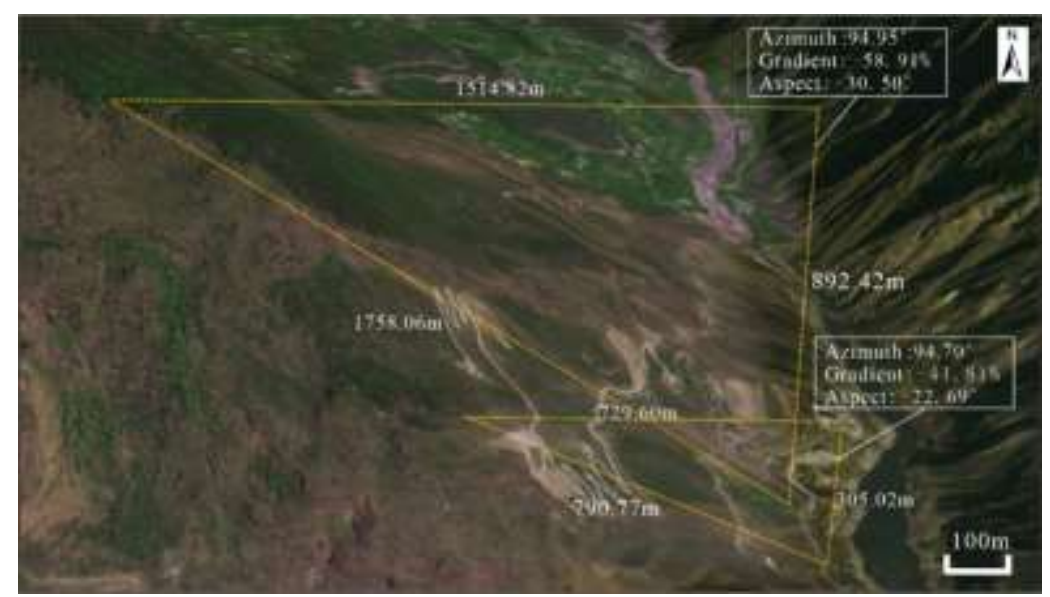

Fig 7 Sketch map of the slope and angle of the study area

The external environmental factors are mainly hydrometeorological conditions, erosion and weathering. Danba County is in the Tibetan Plateau monsoon climate in the Northern Hemisphere subtropical climate zone, located in the Dadu River Valley Watershed. Rainfall is concentrated in June-August, and the annual total precipitation is generally 500-1000 mm. Mountain torrents and mud-rock flows frequently occur in Danba County under the influence of heavy rainfall; for example, the Danba County region suffered 60-year floods in June 2020 under the influence of heavy rainfall, and several places, including Banshanmen, Donggu, and Mozigou, suffered flood debris flows. River erosion is also very strong due to the breaking and cutting of the valley because of the influence of heavy rainfall and strong tectonic activity. The water level rises and falls steeply during the flood season, and the dynamic water pressure and uplift force change rapidly in the slope. When the water level falls rapidly, the abnormal increase in hydrodynamic pressure and the rapid decrease in uplift force play a large role in triggering the failure of the slope, and the foot of the slope is easily cut so that the upper rock mass loses its support, and then, the slope loses its stability.

In addition to the above natural factors, human activities, especially engineering construction disturbance factors, which increase with the development of the social economy, are also important factors affecting the stability of slopes. These effects include engineering cut slopes and slope angles and persistent engineering disturbances. The remote sensing images show that there is a continuous curved road in the middle of the slope. Although the road scale is not large, this curved road has the phenomenon of 
horizontal repeated slope cutting, and there is a large range of construction in the top platform of the observation area, which changes the slope gradient and forms the terrain characteristics mentioned above. The strong deformation area observed by ground radar is located in the upper part of the road construction area. Under the influence of the slope-cutting disturbance, two clear and continuous surface fissures were formed in the upper part of the platform, one of which was more than $900 \mathrm{~m}$ in length and the other was more than $600 \mathrm{~m}$ in length. According to remote sensing image records, roads were built from 2011 to 2012; although the scale was small, roads became one of the important factors that induced slope instability and deformation under the disturbance of long-term human activities.

\subsection{Difference analysis of spaceborne and ground-based observation results}

The main reasons for the inconsistent characterization results of the deformation area between spaceborne InSAR and ground-based radar include the inconsistent time period length of satellite and ground observations, the observation mode and angle of satellite and ground surface, the difference in deformation reference points, the mismatch of image resolution and observation accuracy, and the phase difference.

In terms of the observation time cycle, spaceborne InSAR data were collected from July 2018 to October 2020, with a 12-day interval of 62 scenes. The ground-based radar monitoring time was from September 13 to September 17, 2020. There is a large difference in the observation time and the collection time interval between them. Spaceborne InSAR has a larger time span, longer acquisition interval, and ground-based radar has a smaller time span, shorter acquisition interval, higher time resolution and better data accuracy.

In terms of the difference between the observation mode and the incident angle, the ground-based radar and spaceborne InSAR monitoring schematic diagram is shown in Fig 8. Ground-based radar is installed in a flat field opposite the study area and scanned by a rotating scanner at a set angle. The elevation angle of this experiment is $20^{\circ}$, and the range of radar scanning angles is $-20^{\circ} \sim 20^{\circ}$. Sentinel-1 data have a variety of imaging modes. The interference width mode is the default mode for land cover. 
454 Progressive terrain scanning technology TOPSAR is used to obtain three subbands, and 455 the incident angle is in the range of $29^{\circ} \sim 46^{\circ}$. The imaging mode and the observation 456 angle are different, and the angle of the line-of-sight deformation is also different, 457 which affects the observation result.

458

459
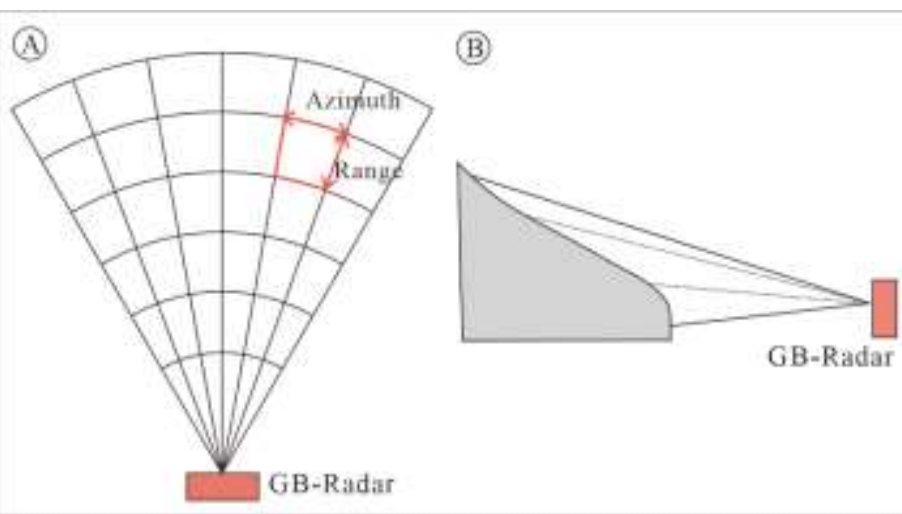

Fig 8(a) Ground-based radar monitoring plan sketch

(b) Ground-based radar monitoring profile sketch (c) A schematic of the Sentinel-1 imaging mode

The reference datum points of deformation are different. The base point of ground-based radar is located at the foot of the slope, so the observed deformation is closer to the real deformation characteristics of the landslide. The spaceborne InSAR data reference point is relatively stable in the whole image, which is located a large distance from the slope, so the deformation shown is also relative to other reference points. There may be overall deformation in a region that either increases or counteracts the true deformation of the slope.

In terms of imaging resolution and deformation monitoring accuracy, the medium resolution of the spaceborne InSAR Sentinel-1 is $5 \mathrm{~m} \times 20 \mathrm{~m}$, and the time series processing accuracy is at the $\mathrm{mm}$ level. The range resolution of the ground-based radar is $0.75 \mathrm{~m}$, and the azimuth resolution at $1 \mathrm{~km}$ is $6.8 \mathrm{mrad}$ with submillimeter accuracy. The data precision of the ground-based radar is obviously higher than that of spaceborne data, but it is not suitable for long-term and large-scale observations, and spaceborne data are not suitable for small-scale deformation objects.

In data processing, the space baseline of ground-based radar is 0 , there is no need for terrain phase compensation, and there is no influence from an orbit error. The influence of the atmosphere is weak due to the limited observation distance. In contrast, 
there is not only the influence of the spatial baseline but also a large interference of atmospheric error in spaceborne InSAR data processing, so it is necessary to repeatedly remove the influence of internal and external noise from various systems, which will greatly reduce the accuracy of the observation data.

\subsection{Applicability of multiple remote sensing platforms for potential geological hazards}

The above studies show that there are usually some differences between the ground-based radar and spaceborne InSAR results of deformation monitoring. These differences are caused by the observation time period, the observation geometric model and incidence angle, the deformation reference point, the image ground resolution and the deformation monitoring accuracy. However, this difference is not due to the large contradiction between the two technical methods but a reasonable physical phenomenon, which is a multiangle solution to a problem and is formed by a variety of physical factors. This finding also reflects the advantages and disadvantages of spaceborne InSAR and ground-based radar in deformation monitoring of geological disasters. Therefore, in actual research, the two methods can be combined to form an effective technical complementary scheme.

By combining satellite data and ground-based monitoring technology, the deformation mechanism and factors influencing geological slopes can be studied from more perspectives and aspects (Yongsheng Li et al. 2020). Topographic transformations produced by human disturbances can be recorded by satellite data with high spatial and temporal resolutions. Due to the limitation of spatial and temporal resolution, the spaceborne InSAR method is suitable for the early identification and investigation of the risk of geological hazards. By comparison, ground-based radar is suitable for geological hazard monitoring, early warning and emergency observation due to its advantages of higher deformation observation precision, flexible observation angle and easy deployment (Caduff et al. 2015; Casagli et al. 2010; Nico et al. 2004; Qin et al. 2020). In addition, ground-based radar is the most suitable technique for deformation observations with high precision in real time to determine the potential of secondary 
507 landslides for safety during emergency responses (Antonello et al. 2004; Atzeni et al. 508 2015) in the postdisaster phase (Luo et al. 2020). In the case of geological hazards, 509 UAVs can be rapidly deployed to capture orthophoto image data to evaluate the 510 influence and damage intensities during a disaster for emergency response purposes for 511 the first time (Casagli et al. 2017; Nikolakopoulos and Koukouvelas 2017).

512 In recent years, advances in earth observation (EO) from the ground surface, 513 aircraft and space have dramatically improved our ability to detect and monitor active 514 landslides (Bardi et al. 2014; Dai et al. 2020; Bardi et al. 2016). Various RS platforms, 515 including satellites, UAVs, ground-based radar instruments, etc., have been widely 516 used in the investigation of geological hazards and in the assessment of disaster 517 emergencies. Because the characteristics of each platform differ from those of other 518 platforms, different RS platforms may play various roles in different phases of 519 landslide hazard evaluations, including the before and after landslide phases. Therefore, 520 different platforms and measurement models may have different applications in 521 various scenarios and stages of disaster evolution due to their different advantages and 522 disadvantages, which can be combined to solve the qualitative investigation and 523 quantitative measurement of hidden geological hazards and their deformation 524 characteristics. With the support of all these platforms, we can study all elements and 525 entire chains of geological disasters. Therefore, satellite-based and ground-based 526 observation technologies can effectively complement each other in the time axis and 527 deepen the understanding of the development trend of geological hazard deformation 528 by constructing the working mechanism of their coordination to provide important 529 technical support to prevent risks of major geological disasters. By summarizing nearly 530 all RS methods suitable for geological hazard investigation, different features and 531 parameters are listed briefly for reference in Table 2 for different scenarios and stages.

532 Table 2 Application characteristics of sky-ground observation technology in geological disaster 533 detection

\begin{tabular}{llllll}
\hline Platform & Advantages & Hazard scene and & & Resolution/Pr & Disadvantages \\
& & stage & Application objective & & \\
\hline \multirow{2}{*}{$\begin{array}{l}\text { Optical } \\
\text { satellite data }\end{array}$} & Wide amplitude, & Early identification & Trace characteristics survey, & Affected by vegetation cover, \\
& & of hidden dangers & disaster risk assessment, & Submetre & affected seriously by weather \\
\hline
\end{tabular}




\begin{tabular}{|c|c|c|c|c|c|}
\hline $\begin{array}{l}\text { Spaceborne } \\
\text { InSAR }\end{array}$ & $\begin{array}{l}\text { Wide amplitude, } \\
\text { all-weather, } \\
\text { all-time }\end{array}$ & $\begin{array}{l}\text { Early identification } \\
\text { of hidden dangers }\end{array}$ & $\begin{array}{l}\text { Survey of deformation } \\
\text { characteristics, disaster risk } \\
\text { assessment, large-scale risk } \\
\text { census }\end{array}$ & $\begin{array}{l}\text { Time series: } \\
\text { mms; } \\
\text { Difference: } \\
\text { cms }\end{array}$ & $\begin{array}{l}\text { Long revisit cycle, current } \\
\text { dependence on foreign } \\
\text { satellites, high-resolution data } \\
\text { is expensive }\end{array}$ \\
\hline $\begin{array}{l}\text { UAV-based } \\
\text { tilt } \\
\text { photogramm } \\
\text { etry }\end{array}$ & $\begin{array}{l}\text { High resolution, 3D } \\
\text { modeling, flexible } \\
\text { deployment }\end{array}$ & $\begin{array}{l}\text { Disaster } \\
\text { investigation, } \\
\text { emergency } \\
\text { assessment }\end{array}$ & $\begin{array}{l}\text { Trace feature survey, disaster } \\
\text { risk verification, disaster } \\
\text { assessment }\end{array}$ & $\mathrm{cms}$ & Small imaging width \\
\hline UAV-SAR & $\begin{array}{l}\text { High resolution, } \\
\text { all-weather, all-day, } \\
\text { flexible deployment }\end{array}$ & $\begin{array}{l}\text { Disaster } \\
\text { investigation, } \\
\text { emergency } \\
\text { assessment }\end{array}$ & $\begin{array}{l}\text { Trace feature survey, disaster } \\
\text { risk verification, disaster } \\
\text { assessment }\end{array}$ & $\mathrm{cms}$ & $\begin{array}{l}\text { UAV-SAR does not support } \\
\text { interference processing and has } \\
\text { small imaging width }\end{array}$ \\
\hline GNSS & $\begin{array}{l}\text { High-precision } \\
\text { real-time } \\
\text { continuous } \\
\text { monitoring }\end{array}$ & $\begin{array}{l}\text { Monitoring, } \\
\text { forecasting and } \\
\text { early warning, } \\
\text { emergency } \\
\text { monitoring }\end{array}$ & $\begin{array}{l}\text { Deformation characteristics } \\
\text { investigation and dynamic } \\
\text { monitoring of landslide } \\
\text { disaster risk }\end{array}$ & $\mathrm{mms}$ & $\begin{array}{l}\text { Sparse points, high observation } \\
\text { cost and insufficient remote } \\
\text { landslide monitoring }\end{array}$ \\
\hline $\begin{array}{l}\text { Ground-base } \\
\text { d radar }\end{array}$ & $\begin{array}{l}\text { All-day, high } \\
\text { precision real-time } \\
\text { continuous } \\
\text { monitoring, can } \\
\text { monitor high } \\
\text { remote landslides }\end{array}$ & $\begin{array}{l}\text { Monitoring, } \\
\text { forecasting and } \\
\text { early warning, } \\
\text { emergency } \\
\text { monitoring }\end{array}$ & $\begin{array}{l}\text { Deformation characteristics } \\
\text { investigation and dynamic } \\
\text { monitoring of landslide } \\
\text { disaster risk }\end{array}$ & submillimeter & $\begin{array}{l}\text { Affected by vegetation and } \\
\text { atmosphere, suitable for single } \\
\text { landslide monitoring }\end{array}$ \\
\hline
\end{tabular}

\section{Conclusion}

536 Based on 656 ground-based radar images collected from September 13-17, 2019, 537 and 62 spaceborne SAR observations from July 2018 to October 2020, this paper 538 analyzed the deformation information extraction of an ancient landslide on the right 539 bank of the Dajinchuan River in Danba County. The maximum deformation area 540 monitored by ground-based radar is located at the upper part of the continuous curve of 541 bedrock on the back wall of the ancient landslide, and the maximum deformation is 542 more than $30 \mathrm{~mm}$. Spaceborne data also measure deformation here, but the measured 543 maximum deformation area is located in the continuous curved area in the lower part of 544 the maximum deformation area observed by ground-based radar, and the annual 545 average deformation rate is more than $40 \mathrm{~mm} / \mathrm{a}$.

546 Combined with the local geological topography, meteorological precipitation and 547 other data, this paper analyzed the main factors affecting the deformation of bedrock in 
548 the region, including geological structure factors, topography and geomorphology

549 factors, hydrological and meteorological conditions, erosion, weathering and human

550 activities. Additionally, we discussed the reasons for the difference in the deformation

551 results between the two observation methods and provided suggestions for the scheme

552 of satellite-ground coobservation. By complementing each other in the time axis, the

553 effectiveness of spaceborne InSAR in the early identification of geological hazard risks

554 and the advantages of ground-based radar for the high-precision observation of key

555 deformation targets were brought into play. The cooperative working mechanism of the

556 two was more conducive to identifying hidden geological hazards and monitoring risk

557 sources.

\section{$558 \quad$ References}

559 Antonello G, Casagli N, Farina P, Leva D, Nico G, Sieber AJ, et al (2004) Ground-based SAR $560 \quad$ interferometry for monitoring mass movements. Landslides 1(1):21-8

561 Atzeni C, Barla M, Pieraccini M, Antolini F (2015) Early Warning Monitoring of Natural and 562 Engineered Slopes with Ground-Based Synthetic-Aperture Radar. Rock Mechanics and Rock Engineering 48(1):235-46

564 Bardi F, Frodella W, Ciampalini A, Bianchini S, Ventisette CD, Gigli G, et al (2014) Integration between ground based and satellite SAR data in landslide mapping: The San Fratello case study. Geomorphology 223

Bardi F, Raspini F, Ciampalini A, Kristensen L, Rouyet L, Lauknes TR, et al (2016) Space-Borne and Ground-Based InSAR Data Integration: The Åknes Test Site. Remote Sensing 8(3)

Caduff R, Schlunegger F, Kos A, Wiesmann A (2015) A review of terrestrial radar interferometry for measuring surface change in the geosciences. Earth Surface Processes and Landforms 40(2):208-28

Casagli N, Catani F, Ventisette CD, Luzi G (2010) Monitoring, prediction, and early warning using ground-based radar interferometry. Landslides 7(3):291-301 
577 Chen H, Xu Y, Zhuang M, Jiang Z, zhang n (2011) Study on the construction of geological disaster emergency support system. The Chinese Journal of Geological Hazard and Control (04):108-11

Chen T (2020) Deformation monitoring of ground-based InSAR based on TCPInSAR technology. China University of Geosciences (Beijing)

Dai K, Peng J, Zhang Q, Wang Z, Liu X (2020) Entering the Era of Earth Observation-Based Landslide Warning Systems: A Novel and Exciting Framework. IEEE Geoscience and Remote Sensing Magazine PP(99)

Donnarumma A, Revellino P, Grelle G (2013) Guadagno FM Slope Angle as Indicator Parameter of Landslide Susceptibility in a Geologically Complex Area. Landslide Science and Practice

Duan A, Xiao Z, Wu G (2016) Characteristics of Climate Change over the Tibetan Plateau Under the Global Warming During 1979-2014. Climate Change Research 12(5)

Li B, Li Y, Jiang W, Cai J, Gan J (2019) Research and Application of Slope Dynamic Monitoring Based on Ground-Based Real Aperture Radar. Geomatics and Information Science of Wuhan University 44(007):1093-8

Li M, Zheng W, Shi S, Xie Z (2008) The revival mechanism and stability analysis to Jiaju Landslide of

$$
\text { Danba County in Sichuan Province. Journal of mountain science (05):69-74 }
$$

Li Y, Jiao Q, Hu X, Li Z, Li B, Zhang J, et al (2020) Detecting the slope movement after the 2018

$$
\text { Baige Landslides based on ground-based and space-borne radar observations. International }
$$
Journal of Applied Earth Observation and Geoinformation 84(C)

Li Y, zhang J, Li Z, Luo Y (2013) Land Subsidence in Beijing City from InSAR Time Series Analysis with Small Baseline Subset. Geomatics and Information Science of Wuhan University 38(011):1374-7

Lu H, Li W, Xu Q, Dong X, Dai C, wang D (2019) Early Detection of Landslides in the Upstream and Downstream Areas of the Baige Landslide, the Jinsha River Based on Optical Remote Sensing and InSAR Technologies. Geomatics and Information Science of Wuhan University 44(9):1342-54

Luo Y, Jiang W, Li B, Jiao Q, Li Y, Li Q, et al (2020) Analyzing the formation mechanism of the Xuyong landslide, Sichuan province, China, and emergency monitoring based on multiple remote sensing platform techniques. Geomatics, Natural Hazards and Risk 11(1):654-77

Nico G, Leva D, Antonello G, Tarchi D (2004) Ground-based SAR interferometry for terrain mapping: 

42(6):1344-50

Nie B (2018) Landslide Deformation Detection and Identification Based on InSAR Technology_ Case of Danba County. Chengdu University of Technology

Nikolakopoulos KG, Koukouvelas I (2017) Emergency response to landslide using GNSS measurements and UAV. Earth Resources \& Environmental Remote Sensing/gis Applications

Qin H, Ma H, Yu Z (2020) Analysis Method of Landslide Early Warning and Prediction Supported by Ground-Based SAR Technology. Geomatics and Information Science of Wuhan University v45(11):50-9

Wang Z, Li Z, Liu Y, Peng J, Mills J (2019) A New Processing Chain for Real-Time Ground-Based SAR (RT-GBSAR) Deformation Monitoring. Remote Sensing 11(20):2437-

Wang Z, Li Z, Mills J (2019) Modelling of instrument repositioning errors in discontinuous Multi-Campaign Ground-Based SAR (MC-GBSAR) deformation monitoring. ISPRS Journal of

620 Wu X, Ma H, zhang J (2019) Development status and application of Ground-Based Synthetic Aperture 621 Radar. Geomatics and Information Science of Wuhan University 044(007):1073-81

622 Xu Q (2020) Understanding and Consideration of Related Issues in Early Identification of Potential 623 Geohazards. Geomatics and Information Science of Wuhan University 45(11):1651-9

624 Zhang L, Liao M, Dong J, Xu Q, Gong J (2018) Early Detection of landslide hazards in mountainous 625 areas of West China using time series SAR interferometry-A case study of Danba, Sichuan. 626 Geomatics and Information Science of Wuhan University 043(012):2039-49

627 Zhang X, Yang H, Jiang J, Peng J, Xu J (2017) GB-InSAR atmospheric delay for highly coherant 628 points correction. Science of Surveying and Mapping 042(001):53-8 


\section{Figures}

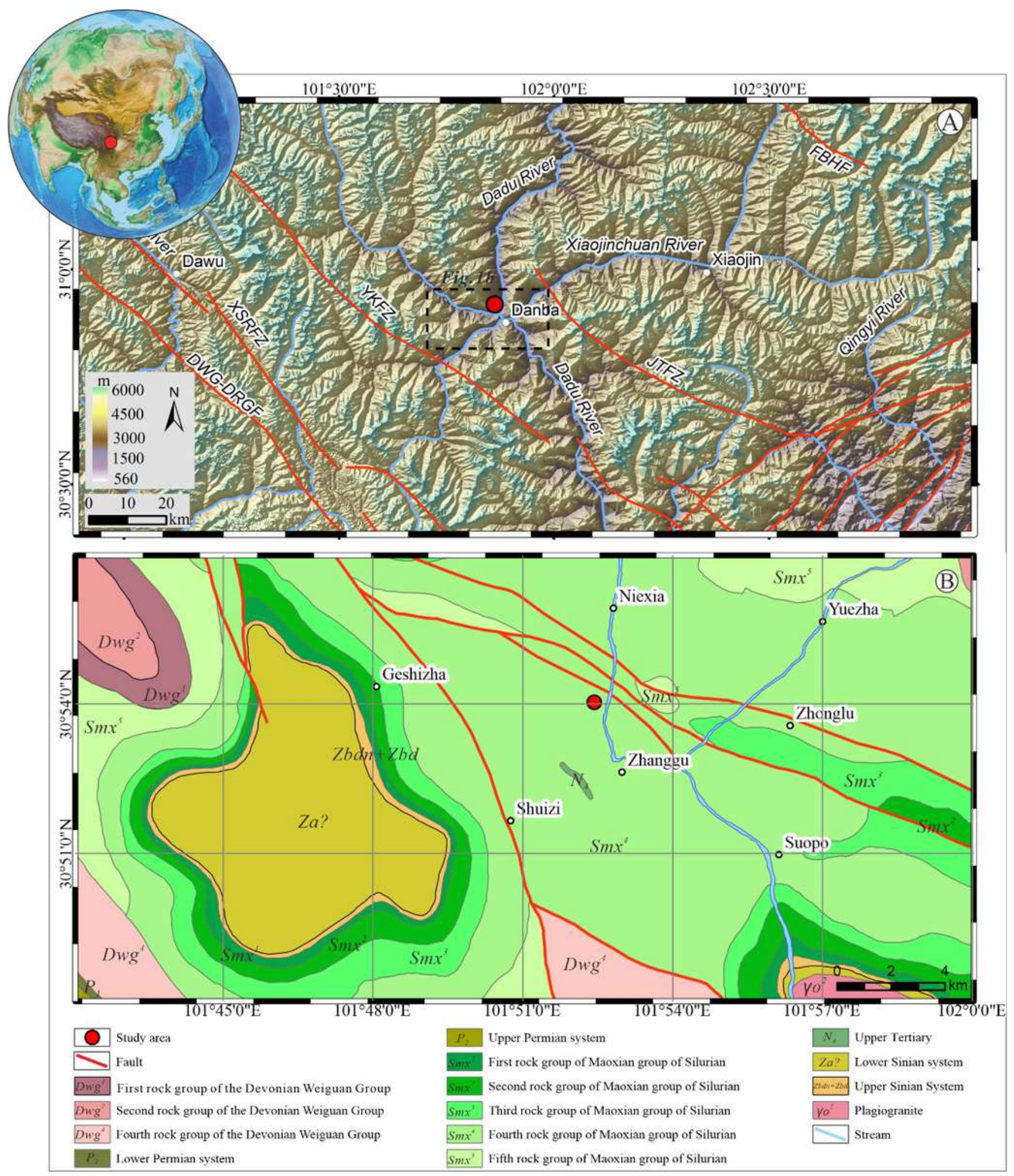

\section{Figure 1}

(a) Regional hillshade map of the study area. A Shuttle Radar Topography Mission (SRTM) hillshade map is used as the base map. (b) Regional geological setting surrounding the study area (China Geological Survey, 2014). The red line denotes the main faults in this region. YKFZ: Yuke fault zone; JTFZ: Jintang 
arc fault; XSHFZ: Xianshui River fault; DWG-GRGF: Dawagou-Dourigou fault; and FBHF: Fubian River fault. Note: The designations employed and the presentation of the material on this map do not imply the expression of any opinion whatsoever on the part of Research Square concerning the legal status of any country, territory, city or area or of its authorities, or concerning the delimitation of its frontiers or boundaries. This map has been provided by the authors.
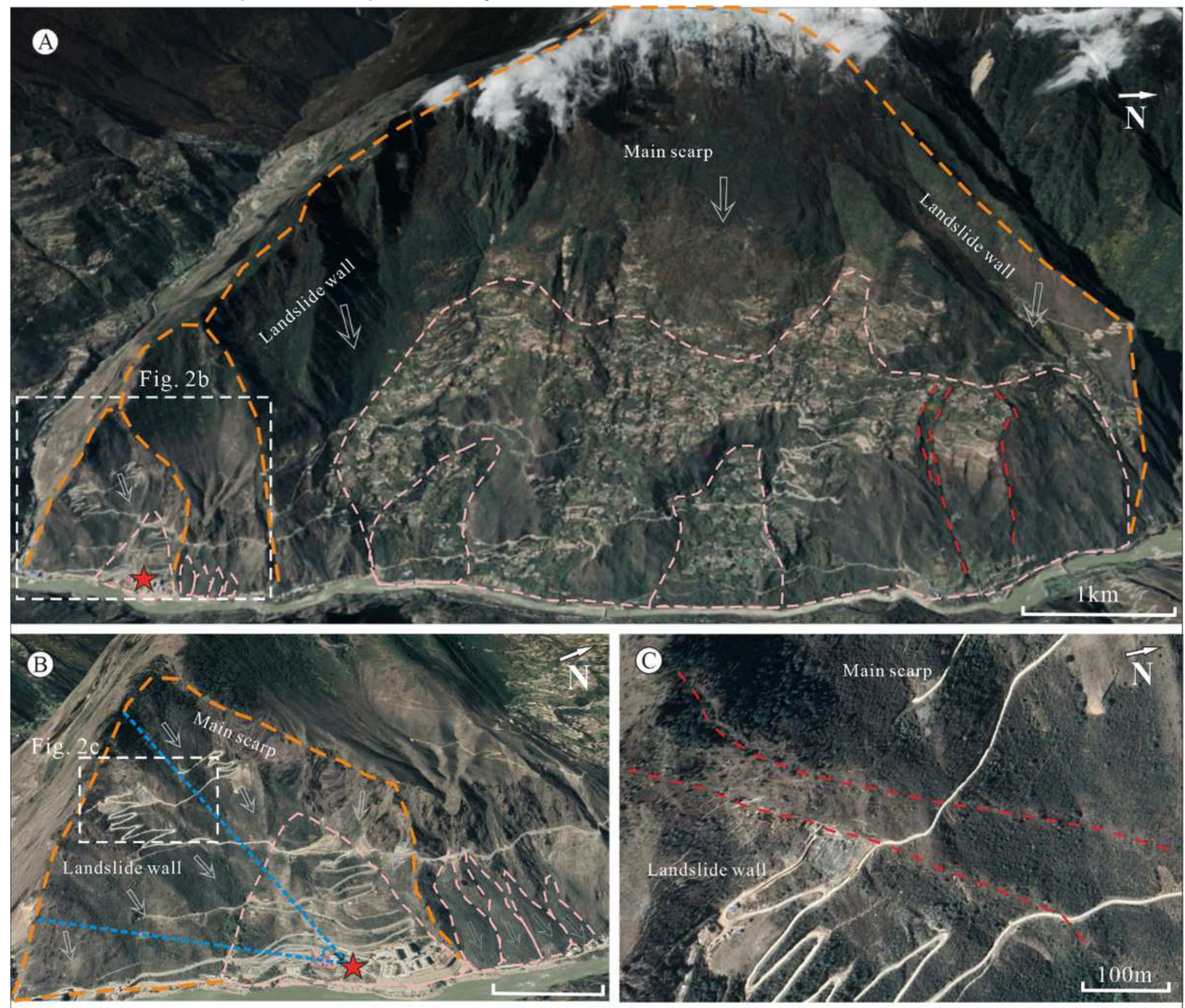

- Observation location

Wh and range of GB-Radar

Debris mass of ancient landslide
Slide direction of the ancient landslide
, Main scarp and wall of

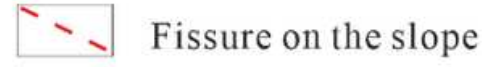

\section{Figure 2}

Geographic location map. (a) The whole picture of the Jiaju landslide group. (b)The location and range of ground-based radar. (c) The surface fissure on the slope. Note: The designations employed and the 
presentation of the material on this map do not imply the expression of any opinion whatsoever on the part of Research Square concerning the legal status of any country, territory, city or area or of its authorities, or concerning the delimitation of its frontiers or boundaries. This map has been provided by the authors.
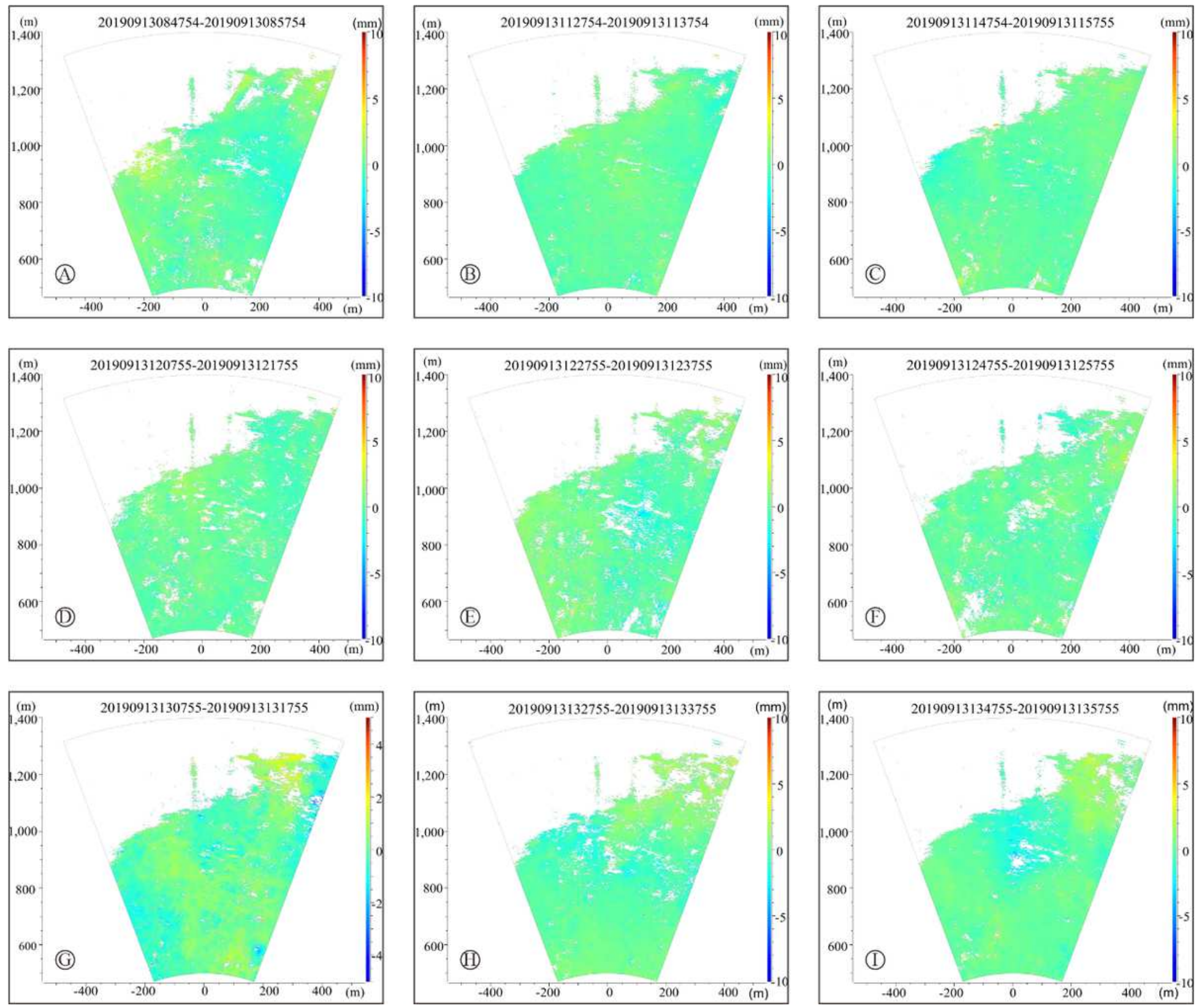

Figure 3

Examples of differential interferograms generated during the processing of ground-based radar data. The two numbers in the upper part of each figure denote the observation dates of two data points used to generate the differential interferogram. 20190913084754-20190913085754 denotes the differential interferogram generated between two data points observed at $8 \mathrm{~h} 47 \mathrm{~m} 54 \mathrm{~s}$ on September 13, 2019, and at $8 \mathrm{~h} 57 \mathrm{~m} 54 \mathrm{~s}$ on September 13,2019. The origin point of the coordinate system is the position of the ground-based radar. 


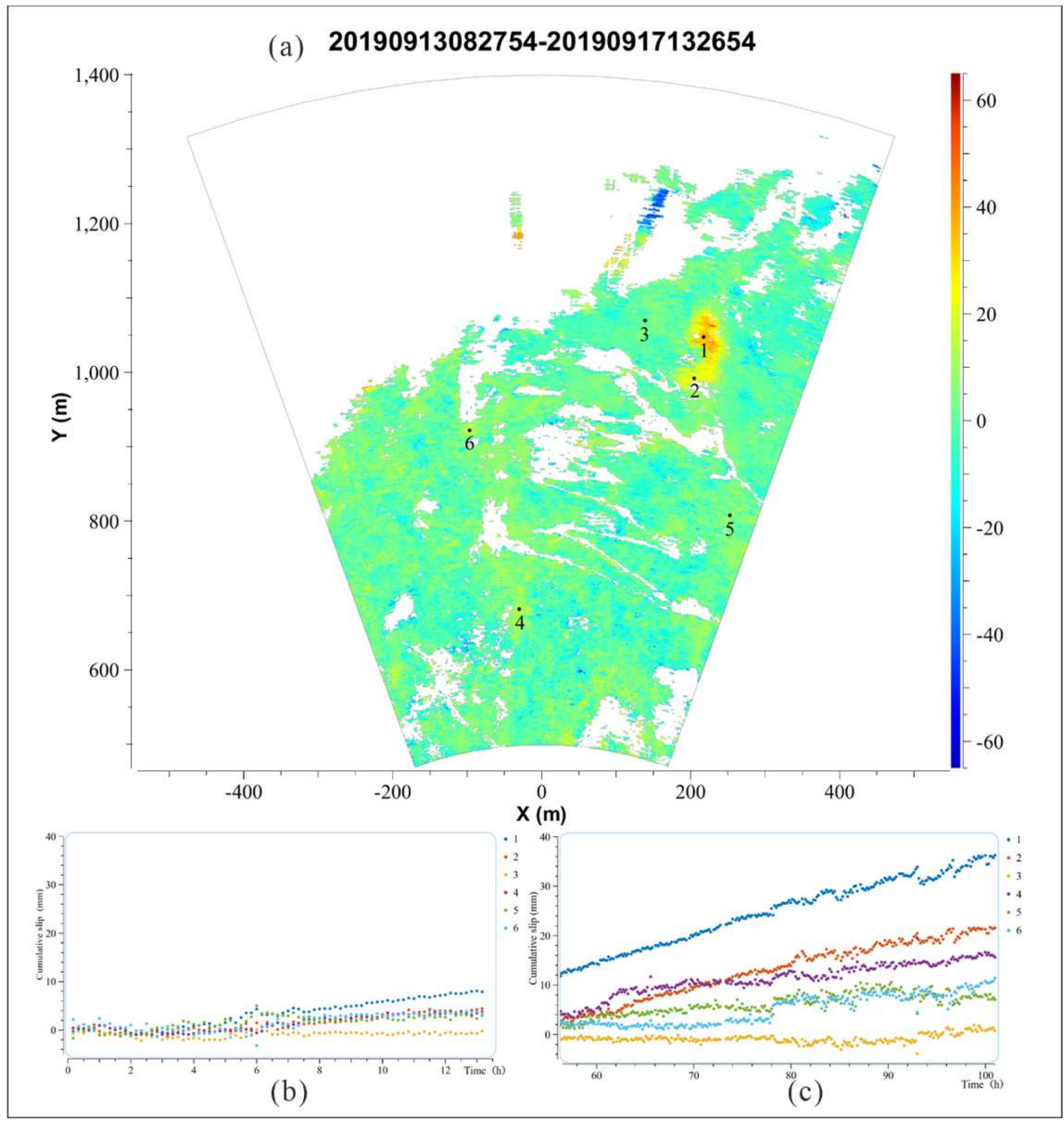

\section{Figure 4}

(a) Cumulative slips of the slope deformation along the LOS direction measured by the ground-based radar device. The number at the top of the figure represents the time when ground-based radar began and ended observations, that is, the observation time range of the cumulative deformation map generated; and 20190913082754-20190917132654 represents ground-based radar observation time from 8:27:54 on September 13, 2019 to 13:26:54 on September 17, 2019. The origin of the coordinates represents the 
position of the ground-based radar. (b) and (c) are the results of the accumulated deformation of the selected points in the time series of $0 \sim 13.5 \mathrm{~h}$ and $56 \sim 101 \mathrm{~h}$, respectively.

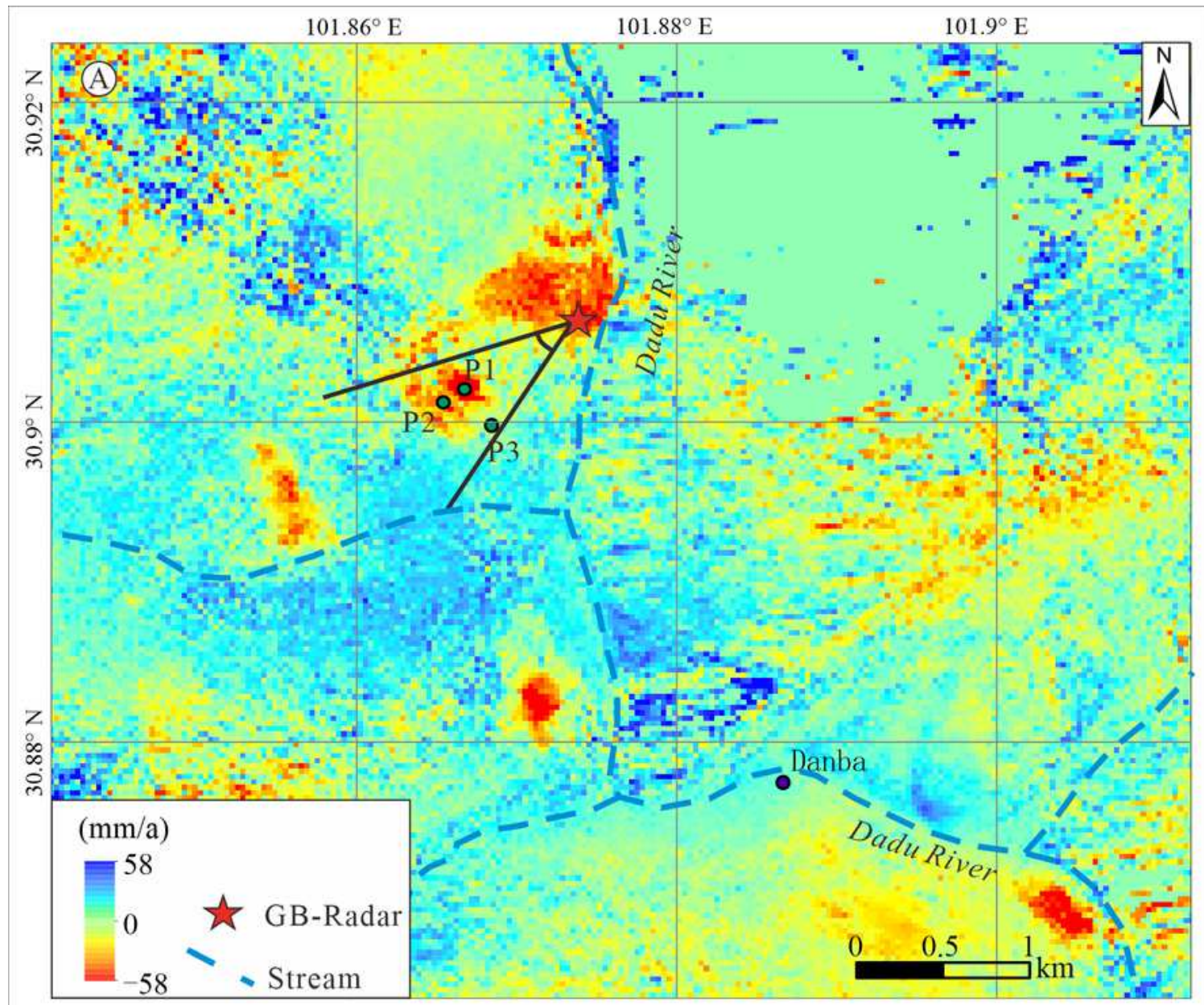

(B)

Time series analysis

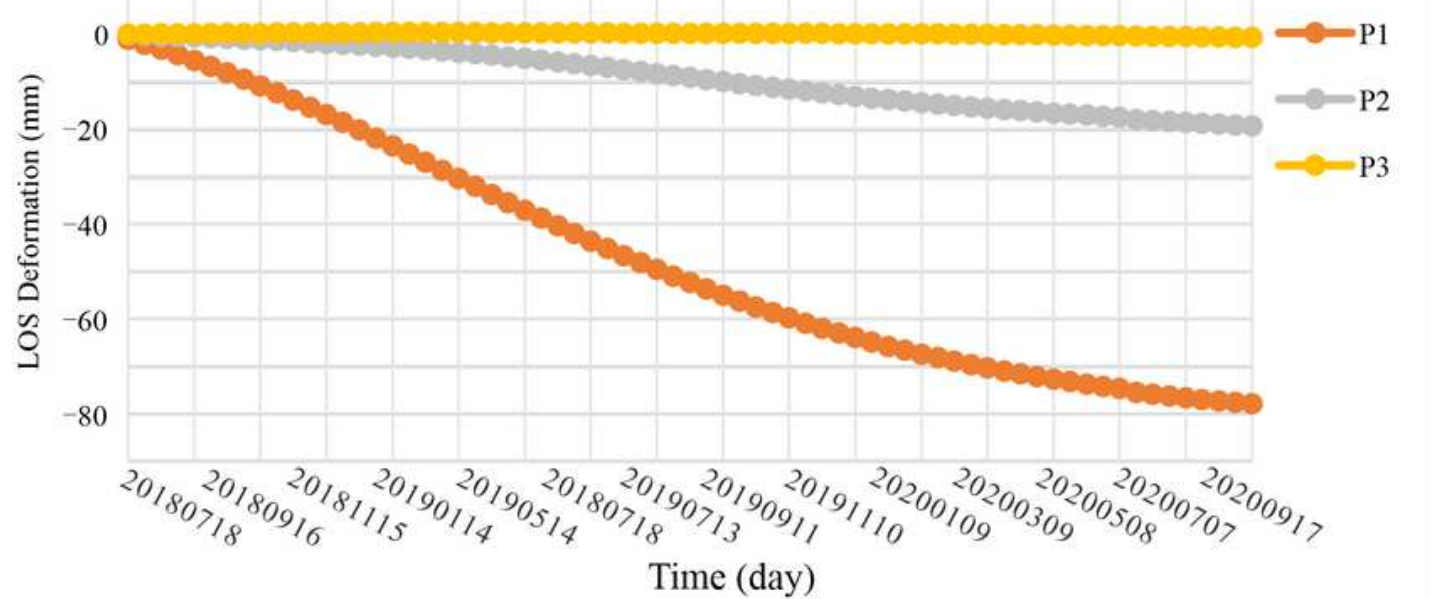

Figure 5

(a) Regional annual deformation rate map measured by Sentinel-1 data, and P1, P2 and P3 are the three points selected in the observation area of ground-based radar. The gray line is the scanning angular scope of ground-based radar. (b) The line-of-sight cumulative deformation map of three selected points 
P1, P2 and P3 in the study area. Note: The designations employed and the presentation of the material on this map do not imply the expression of any opinion whatsoever on the part of Research Square concerning the legal status of any country, territory, city or area or of its authorities, or concerning the delimitation of its frontiers or boundaries. This map has been provided by the authors.

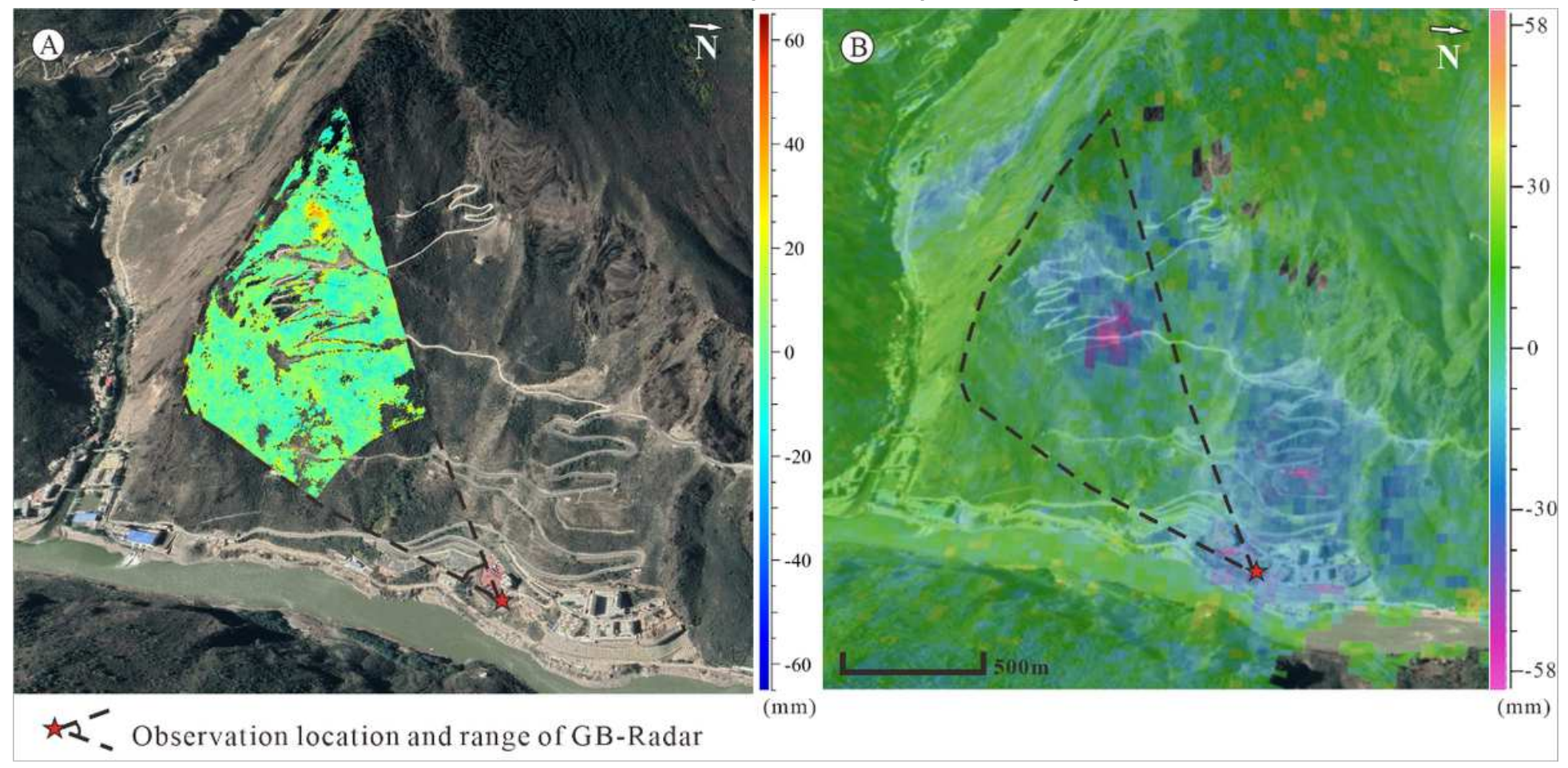

Figure 6

(a) Map of ground-based radar monitoring results superimposed on Google Earth; (b) Map of Sentinel 1 monitoring results superimposed on Google Earth. Note: The designations employed and the presentation of the material on this map do not imply the expression of any opinion whatsoever on the part of Research Square concerning the legal status of any country, territory, city or area or of its authorities, or concerning the delimitation of its frontiers or boundaries. This map has been provided by the authors. 


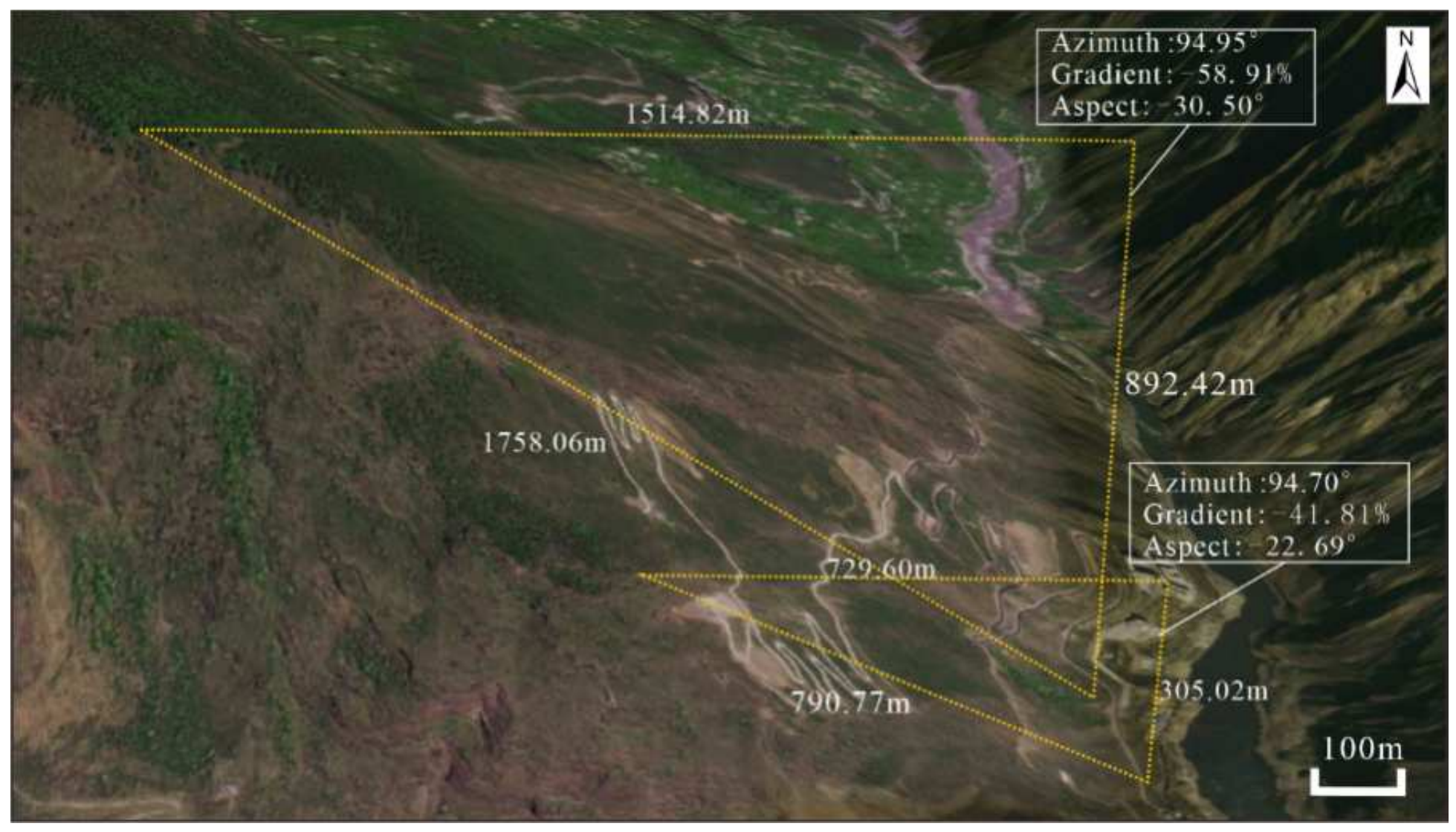

\section{Figure 7}

Sketch map of the slope and angle of the study area Note: The designations employed and the presentation of the material on this map do not imply the expression of any opinion whatsoever on the part of Research Square concerning the legal status of any country, territory, city or area or of its authorities, or concerning the delimitation of its frontiers or boundaries. This map has been provided by the authors.

(A)

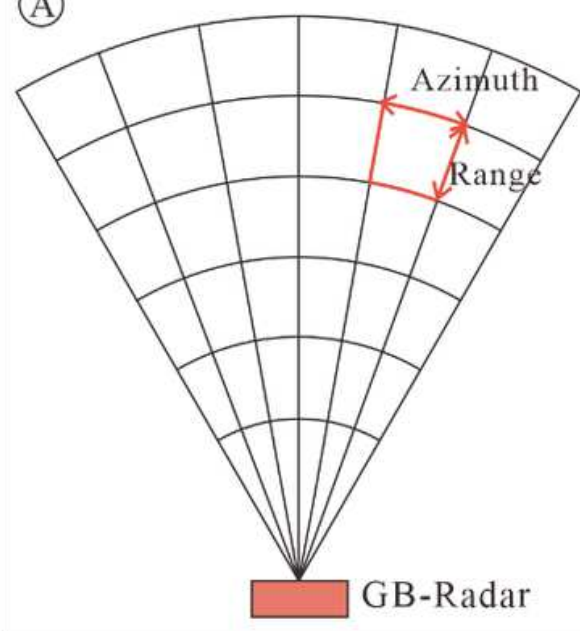

\section{(B)}

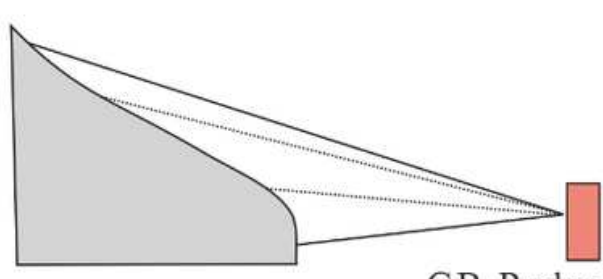

GB-Radar (c)
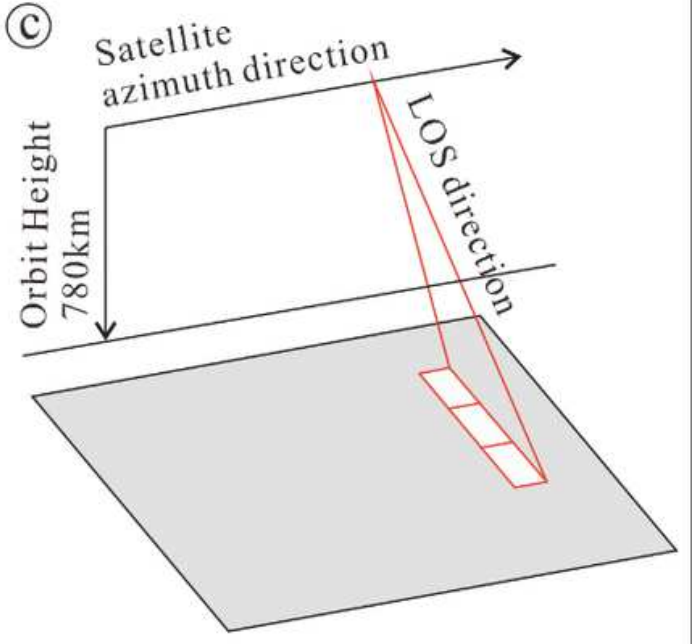

\section{Figure 8}


(a) Ground-based radar monitoring plan sketch (b) Ground-based radar monitoring profile sketch (c) A schematic of the Sentinel-1 imaging mode 